
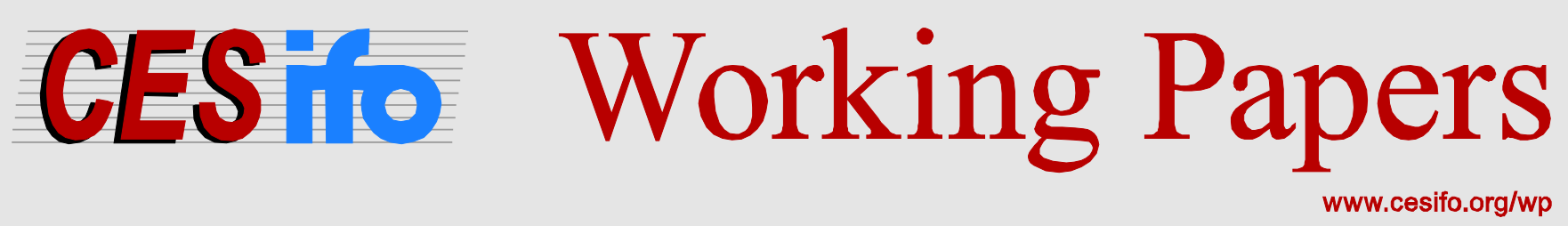

\title{
Fiscal Multipliers in a Two-Sector Search and Matching Model
}

\author{
Konstantinos Angelopoulos \\ Wei Jiang \\ James Malley
}

\author{
CESIFO WORKING PAPER NO. 5197 \\ CATEgory 6: Fiscal Policy, MaCROECONOMICS AND GROWTH \\ JANUARY 2015
}

ISSN 2364-1428

An electronic version of the paper may be downloaded

- from the SSRN website:

- from the RePEc website:

- from the CESifo website:

WWW.SSRN.com

www.RePEc.org

www.CESifo-group.org/wp 


\title{
Fiscal Multipliers in a Two-Sector Search and Matching Model
}

\begin{abstract}
This paper evaluates the effects of policy interventions on sectoral labour markets and the aggregate economy in a business cycle model with search and matching frictions. We extend the canonical model by including capital-skill complementarity in production, labour markets with skilled and unskilled workers and on-the-job-learning (OJL) within and across skill types. We first find that, the model does a good job at matching the cyclical properties of sectoral employment and the wage-skill premium. We next find that vacancy subsidies for skilled and unskilled jobs lead to output multipliers which are greater than unity with OJL and less than unity without OJL. In contrast, the positive output effects from cutting skilled and unskilled income taxes are close to zero. Finally, we find that the sectoral and aggregate effects of vacancy subsidies do not depend on whether they are financed via public debt or distorting taxes.
\end{abstract}

JEL-Code: E240, E320, J630, J640, J680.

Keywords: fiscal multipliers, sectoral labour markets, search and matching.

Konstantinos Angelopoulos

University of Glasgow / UK

k.angelopoulos@lbss.gla.ac.uk
Wei Jian*

University of Kent / UK

w.jiang@kent.ac.uk

\author{
James Malley \\ University of Glasgow / UK \\ j.malley@lbss.gla.ac.uk
}

*corresponding author

January 25, 2015

We would like to thank Pedro Gomes, Amanda Gosling, Miguel León-Ledesma, Mathan Satchi, Fabien Postel-Vinay and participants at the Computing in Economics and Finance, 2014 conference in Oslo and the University of Kent Workshop on Labour Market, Public Policy and the Business Cycle for helpful comments and suggestions. 


\section{Introduction}

Equilibrium unemployment models with search and matching frictions have been extensively used in macroeconomic analyses of unemployment (see e.g. Shimer (2010) and Rogerson and Shimer (2011) for an analytical overview of this research). Among other extensions, this literature has considered the importance of both differences in workers' skills and the potential for skill erosion due to unemployment (see e.g. Cahuc et al. (2006), Krause and Lubik (2006 and 2010), Dolado et al. (2009), Hagedorn et al. (2010), Doppelt (2014) and Laureys (2014)). In this paper, we contribute to this literature by examining unemployment over the business cycle in an economy with fragmented labour markets for University educated (or skilled) and nonUniversity educated (or unskilled) workers, when the production structure is characterised by capital-skill complementarity and workers' productivity decreases with unemployment.

Our interest in labour markets and unemployment for skilled versus unskilled workers is motivated by empirical evidence on the importance of the differences between these two labour markets, regarding both wage and employment rates. We summarise some key differences using quarterly data for the U.S. over the period of 1992-2011 for sectoral employment and 1979-2003 for wage inequality. ${ }^{1}$

First, the literature on the skill premium has demonstrated that there are significant differences in the wages across the two sectors. In particular, wage inequality between skilled and unskilled labour has increased in recent decades to its highest levels in a century (see e.g. Goldin and Katz (2008) and Acemoglu and Autor (2011) for a discussion of longer time series and historical data). This is demonstrated in the subplot $(1,1)$ of Figure 1 , which plots the skill premium, defined as the ratio of skilled to unskilled wage, using the quarterly series from Castro and Coen-Pirani (2008).

Second, wage inequality varies in business cycle frequencies, although less than output and is not strongly correlated with output (see also e.g. Lindquist (2004) and Pourpourides (2011)). This is captured in subplot $(2,1)$ which shows HP-filtered output and the skill premium. In particular, the relative to output volatility of the skill premium is 0.87 and its output

\footnotetext{
${ }^{1}$ The data sources for the skilled and unskilled wage data (1979-2003) are from the dataset of Castro and Coen-Pirani (2008). Sectoral employment/unemployment data (1992-2011) are from the Current Population Survey, Table A-4. We use data on the employment status of the civilian population 25 years and over by educational attainment (see www.bls.gov/webapps/legacy/cpsatab4.htm). Finally, per capita quarterly output data (1979-2011) are from the U.S. NIPA.
} 
correlation is 0.086 .

[Figure 1 here]

Third, employment differs significantly between the two sectors. For example, the data in subplot $(1,2)$, show that unemployment is twice as high for unskilled compared with skilled workers. ${ }^{2}$ Moreover, as demonstrated in subplot $(2,2)$, unskilled employment is more volatile than skilled, although both closely track cyclical output. In particular, the volatility of the HP-filtered unskilled employment is 1.8 times higher than that of skilled workers, whereas their output correlations are about 0.93 .

The literature has documented further differences between the skilled and unskilled sectors. Cahuc et al. (2006) find that skilled workers have higher bargaining power, while Pissarides (1994), Acemoglu (2001) and Krause and Lubik (2006 and 2010) suggest that the flow cost of posting a vacancy is higher in 'good' jobs. Moreover, in business cycle frequencies, there is not much movement between the skilled and unskilled sectors.

In light of the above, we build a business cycle model with search and matching frictions that lead to sectoral unemployment. To capture the above empirical observations, we first assume that unskilled workers cannot become skilled. Instead, skilled workers work in skilled jobs and, if unemployed, search for employment in the skilled sector. Similarly, unskilled workers work in unskilled jobs, and if unemployed, search for employment in the unskilled sector. Second, we assume that the production structure allows for skillbiased technical change and, in particular, is characterised by capital-skill complementarity. This setup has been shown to explain key characteristics of the skill premium in the data, both in terms of its evolution over the past several decades (see e.g. Katz and Murphy (1992), Krusell et al. (2000) and He (2012)) as well as over the business cycle (Lindquist (2004) and Pourpourides (2011)). The search and matching mechanism for employment creation that we employ follows the benchmark Mortensen-Pissarides framework with the wage being determined via Nash bargaining. Moreover, our setup allows for differentiation between the two labour markets, such as differences in relative bargaining power, job separation rates and job posting costs to reflect the empirical observations outlined above.

Motivated by theories of labour augmenting technical progress driven by on-the-job learning $(O J L)$, we allow skilled and unskilled workers' productivities to be positive functions of employment. Alternatively, since the sectoral productivities are decreasing functions of unemployment, they can equivalently capture skill erosion due to not working. We consider two possibilities

\footnotetext{
${ }^{2}$ Fallick and Fleischman (2004), Hagedorn et al. (2010), and Pilossoph (2012) also document higher job separation rates for unskilled versus skilled workers.
} 
for $O J L$ where both skill types learn from their own and the other skill type.

The first follows the literature that proposes learning-by-doing $(L B D)$ as a property of the production technology at the aggregate level and generates knowledge spillovers. It thus works as an external effect for the individual (see e.g. Romer (1986) and Barro and Sala-i-Martin (1994)). In this case the workers' labour productivity depends on average employment, so that $L B D$ is taken as given at the level of the workers. The second follows more closely the literature on skill erosion that is due to unemployment (see e.g. Laureys (2014) and Doppelt (2014)). In this instance we allow the workers of each type to internalise the effect of their own employment on their labour productivity. However, we maintain the assumption that the employment of the other worker type is taken as given.

The model is calibrated to match the steady-state of aggregate and sectoral labour market data in the U.S., following the calibration strategy in Shimer (2010). We find that the calibration does a good job at matching the second moments in the sectoral labour market data. In particular, the model predicts a volatility for unskilled employment that is about twice as big as that of skilled employment. Moreover, it predicts a series for the skill premium whose volatility is less than output and its correlation with output is around zero. Consistent with the results in Shimer, the model under predicts quantitatively the volatility of employment, but the gap is not very big. In particular, the model variants considered predict an employment volatility which ranges from $69 \%$ to $81 \%$ of the volatility of employment in the data, whereas in the canonical models, e.g. Shimer (2010), this ratio is typically about $25 \%$. Since the model with and without $O J L$ gives a relatively similar fit to the data, we present results below for policy interventions using both specifications.

Our policy analysis evaluates the effects of temporary interventions on the sectoral labour markets and the aggregate economy. We consider vacancy subsidies and taxes, since as is demonstrated in Monacelli et al. (2010), pure fiscal spending effects on output are trivial and even negative in search and matching models. We find fiscal multipliers on output from the subsides to skilled and unskilled vacancies, which are greater than unity when $O J L$ is external and near unity when it is internal. These large multipliers are determined by the crowding-in of private investment, which follows the increases in employment and labour productivity. Without $O J L$, the labour productivity channel is absent and causes the output multipliers to fall to about 0.6. In contrast to the vacancy subsidies, the positive output effects from cutting skilled and unskilled income taxes are near zero, irrespective of the presence, or model, of $O J L$. We finally find that the effects of the two vacancy subsidies do not depend on whether debt or distorting taxes 
are used to finance them. This is particularly good news, and suggests that this type of intervention may be useful under the debt restrictions that many governments now face in the wake of the financial crisis.

The rest of the paper is organised as follows. Section 2 sets out the model structure. Section 3 presents the calibration and cyclical properties of the model. Section 4 undertakes the fiscal multiplier analysis and Section 5 concludes.

\section{The model}

\subsection{Capital-skill complementarity}

There are $N$ firms which operate in competitive product markets. To produce a single output, firms use capital, which they lease from the household, and skilled and unskilled workers. The production technology is characterised by capital-skill complementarity (see e.g. Goldin and Katz (2008) for historical evidence on the empirical relevance of this technology in the 20th century). In particular, a representative firm produces output $y_{t}^{f}$, using a constant elasticity of substitution (CES) specification following e.g. Krusell et al. (2000):

$$
y_{t}^{f}=A_{t}\left\{\theta\left(l_{t}^{f, u}\right)^{\alpha}+(1-\theta)\left[\rho\left(k_{t}^{f}\right)^{\nu}+(1-\rho)\left(l_{t}^{f, s}\right)^{\nu}\right]^{\frac{\alpha}{\nu}}\right\}^{\frac{1}{\alpha}}
$$

where $A_{t}>0$ is the level of total factor productivity (TFP); $\alpha, \nu<1$ are the parameters determining the factor elasticities, i.e. $1 /(1-\alpha)$ is the elasticity of substitution between capital and unskilled labour and between skilled and unskilled labour, whereas $1 /(1-\nu)$ is the elasticity of substitution between capital and skilled labour; and $0<\theta, \rho<1$ are the factor share parameters. In this specification, $k_{t}^{f}$ is the quantity of capital used by the firm, whereas $l_{t}^{f, s}$ and $l_{t}^{f, u}$ denote the quantities of skilled and unskilled labour respectively.

\section{2 $\quad$ Skilled and unskilled workers}

There is a representative household whose members include skilled or unskilled workers. The workers are distinct units and can offer either skilled or unskilled services in the labour markets. They can find a job within the skill sector in which they belong or remain unemployed. In the latter case, they search for a job for the next time period within their skill sector. In other words, in business cycle frequencies workers cannot change their skill status. This assumption is motivated by empirical evidence suggesting that over the 
business cycle, the share of college educated or skilled population has low volatility and is effectively uncorrelated with output. In particular, using the data in Acemoglu and Autor (2011), we find that the standard deviation of the cyclical component of the skilled population share, relative to that of output, is 0.29 , while its correlation with output is $-0.23 .^{3}$ This implies that skilled workers can either work in skilled jobs or remain unemployed (and search for skilled jobs), whereas unskilled workers can either work in unskilled jobs or remain unemployed (and search for unskilled jobs). Following the literature on search frictions and unemployment in macroeconomic DGE models since Mertz (1995), we assume that the head of the household makes all decisions on behalf of its members and provides complete consumption insurance. In other words, all workers consume the same amount of goods, irrespective of their labour market status, i.e. regardless of whether they are employed in skilled or unskilled jobs or they are unemployed.

The numbers of skilled and unskilled members for the representative household are denoted as $N^{s}$ and $N^{u}$, respectively. The total size of the household is normalised to be $N$ and is thus given as: $N=N^{s}+N^{u}$. The respective population shares of skilled and unskilled members within a household are defined as: $n^{s}=N^{s} / N$ and $n^{u}=N^{u} / N$. We assume that population and its composition remain constant.

For each skill type of household members, $i=s, u$, the number of members/workers can be further decomposed into employed and unemployed members, such that:

$$
N^{i}=N_{t}^{i, e}+N_{t}^{i, s}
$$

where $i=s, u$ for skilled and unskilled labour; and $N_{t}^{i, e}$ is the number of employed members and $N_{t}^{i, s}$ is the number of unemployed members, who are searching for a job. By normalising by $N^{i}$, we have:

$$
1=e_{t}^{i}+s_{t}^{i}
$$

where $e_{t}^{i} \equiv \frac{N_{t}^{i, e}}{N^{i}}$ is the employment rate and $s_{t}^{i} \equiv \frac{N_{t}^{i, s}}{N^{i}}$ is the unemployment rate or the share of workers searching for a job.

\subsection{Search and matching}

There are two labour markets, for skilled and unskilled workers respectively. Each unemployed worker needs to search for a job in the skilled or unskilled

\footnotetext{
${ }^{3}$ This is obtained using annual data for the share of college educated population measured in efficiency units, 1963-2008, from Acemoglu and Autor (2011) and GDP per capita data from the U.S. National Income and Product Accounts (NIPA). The cyclical component of the series is obtained using the HP-filter with a smoothing parameter of 100 .
} 
sector, given her skill level, and can be matched with a firm that posts vacancies in that sector. As in the standard search-and-matching literature (see e.g. Pissarides (1986) and Blanchard and Diamond (1989)), the matching technology is represented by a Cobb-Douglas (CD) function for both skilled and unskilled labour:

$$
M_{t}^{i}=\chi^{i}\left(S_{t}^{i}\right)^{\eta^{i}}\left(V_{t}^{i}\right)^{1-\eta^{i}}
$$

where, $M_{t}^{i}$ is the aggregate new matches at $t{ }^{4} S_{t}^{i}=N^{i} s_{t}^{i}$ denotes the aggregate number of unemployed searching in labour market $i ; V_{t}^{i}=N v_{t}^{i}$ denotes the aggregate number of job vacancies created by firms in labour market $i ; \chi^{i}>0$ represents the constant efficiency of matching for labour type $i$; $0<\eta^{i}<1$ denotes the elasticity of searches for labour type $i$. In addition, we define the vacancy-to-unemployed ratio, $z_{t}^{i}=V_{t}^{i} / S_{t}^{i}=v_{t}^{i} /\left(n^{i} s_{t}^{i}\right)$, as the tightness of type $i$ labour market. The smaller the ratio of $z_{t}^{i}$, the tighter the labour market and therefore the harder for unemployed workers to match with job vacancies.

The probability at which aggregate job searches lead to a new job match in type $i$ labour market is given by:

$$
p_{t}^{i}=\frac{M_{t}^{i}}{S_{t}^{i}}=\chi^{i}\left(S_{t}^{i}\right)^{\eta^{i}-1}\left(V_{t}^{i}\right)^{1-\eta^{i}}=\chi^{i}\left(z_{t}^{i}\right)^{1-\eta^{i}}
$$

and its inverse, $1 / p_{t}^{i}$, measures the duration of type $i$ search.

The probability at which a job vacancy can be matched with an unemployed household member is calculated by:

$$
q_{t}^{i}=\frac{M_{t}^{i}}{V_{t}^{i}}=\chi^{i}\left(S_{t}^{i}\right)^{\eta^{i}}\left(V_{t}^{i}\right)^{-\eta^{i}}=\chi^{i}\left(z_{t}^{i}\right)^{-\eta^{i}}
$$

and its inverse, $1 / q_{t}^{i}$, measures the duration of type $i$ job vacancy.

\subsection{Household}

There is a representative household comprised of skilled and unskilled individuals whose head makes all decisions on behalf of its members by guaranteeing equal consumption to each of them, with the objective of maximising household welfare.

\footnotetext{
${ }^{4}$ In what follows, we use upper case letters for aggregate quantities and lower case letters for per capita quantities.
} 


\subsubsection{Problem}

The representative household maximises discounted lifetime utility, $U_{t}$ :

$$
U_{t}=E_{t} \sum_{t=0}^{\infty} \beta^{t} u_{t}
$$

where $E_{t}$ is the conditional expectations operator at period $t$; and $0<\beta<$ 1 denotes the constant rate of time preference. The instantaneous utility function of the household is given by (see e.g. Shimer (2010)):

$$
u_{t}=\ln \left(c_{t}\right)-n^{s} \xi e_{t}^{s}-n^{u} \xi e_{t}^{u}
$$

where $\xi>0$ is the preference parameter that measures the disutility cost of employment and $c_{t}$ is the household's average (or per capita) private consumption. As is common in the literature, the disutility cost captures the reduction in the time available for home production when a member finds employment. Hence, the specification in (8) assumes that all members consume $c_{t}$ and that if a member is unemployed, her utility is given by $\ln \left(c_{t}\right)$, whereas if a member is employed, her utility is given by $\ln \left(c_{t}\right)-\xi^{i}$, so that $u_{t}$ measures average utility for the household.

The budget constraint of the household is:

$$
\begin{aligned}
& c_{t}+i_{t}+b_{t+1}=\left[r_{t}-\tau_{t}^{k}\left(r_{t}-\delta\right)\right] k_{t}+\pi_{t}+ \\
& +R_{t}^{b} b_{t}+\left(1-\tau_{t}^{s}\right) n^{s} w_{t}^{s} e_{t}^{s} Z_{t}^{s}+\left(1-\tau_{t}^{u}\right) n^{u} w_{t}^{u} e_{t}^{u} Z_{t}^{u}
\end{aligned}
$$

where $i_{t}$ is household's average private investment; $b_{t+1}$ is the value of government bonds bought at period $t ; r_{t}$ is the gross return to physical capital; $\tau_{t}^{k}$ is the tax rate on capital income; $0<\delta<1$ is the constant depreciation rate of physical capital; $k_{t}$ is the average physical capital held by the household at the beginning of $t ; \pi_{t}$ is average dividends received from the firms; $R_{t}^{b}=\left(1+r_{t}^{b}\right)$ is the gross return to bonds; $\tau_{t}^{i}$ is the labour income tax; $w_{t}^{i}$ is the gross wage rate; and $Z_{t}^{i}$ represents labour augmenting technology driven by $O J L$. This technology positively depends on the level of employment. Alternatively, $Z_{t}^{i}$ can be interpreted as a decreasing function of unemployment and captures skill erosion due to not working. ${ }^{5}$ We allow for both skill types to learn on-the-job from their own and the other skill type.

We consider two possibilities for $O J L$. The first follows the literature that proposes learning-by-doing $(L B D)$ as a property of the production technology at the aggregate level. This setup generates knowledge spillovers at the

\footnotetext{
${ }^{5}$ See, for example, Davis and von Wachter (2011) and Pollack (2013) for the effects of unemployment on labour productivity and Laureys (2014) and Doppelt (2014) for search and matching models with skill depreciation due to unemployment.
} 
aggregate level which work as an external effect for the individual (see e.g. Romer (1986) and Barro and Sala-i-Martin (1994)). In this case, we allow the worker's labour productivity to depend on average employment, so that $L B D$ (or, alternatively, skill erosion) is taken as given at the level of the worker. This case is represented as follows:

$$
\begin{aligned}
& Z_{t}^{s} \equiv Z_{t}^{s, x}=\Omega^{s}\left(\bar{e}_{t}^{s}\right)^{\zeta^{s}}\left(\bar{e}_{t}^{u}\right)^{1-\zeta^{s}} \\
& Z_{t}^{u} \equiv Z_{t}^{u, x}=\Omega^{u}\left(\bar{e}_{t}^{s}\right)^{\zeta^{u}}\left(\bar{e}_{t}^{u}\right)^{1-\zeta^{u}}
\end{aligned}
$$

where a bar over a variable refers to average quantities; $\Omega^{i}>0$ are learning productivity parameters; and $0<\zeta^{i}<1$, are the elasticities of $O J L$ with respect to skilled employment for skilled and unskilled workers.

We will proceed with the model solution below using (10) and (11). However, we will also present and discuss results using a second possibility for the determination of $Z_{t}^{i}$, following more closely the literature on skill erosion that is due to unemployment (see e.g. Laureys (2014) and Doppelt (2014)). This alternative assumes that workers internalise the effect of employment on their labour productivity. Hence, in this case we allow the worker of each type to internalise the effect of their own employment on their labour productivity. However, we maintain the assumption that the employment of the other worker type is taken as given: ${ }^{6}$

$$
\begin{gathered}
Z_{t}^{s} \equiv Z_{t}^{s, n}=\Omega^{s}\left(e_{t}^{s}\right)^{\zeta^{s}}\left(\bar{e}_{t}^{u}\right)^{1-\zeta^{s}} \\
Z_{t}^{u} \equiv Z_{t}^{u, n}=\Omega^{u}\left(\bar{e}_{t}^{s}\right)^{\zeta^{u}}\left(e_{t}^{u}\right)^{1-\zeta^{u}} .
\end{gathered}
$$

The capital stock evolves according to:

$$
k_{t+1}=(1-\delta) k_{t}+\tilde{A}_{t}^{k} i_{t}
$$

The capital evolution equation allows for an exogenous process, $\tilde{A}_{t}^{k}$, capturing an investment-specific technological (IT) change, which has been shown to contribute to output fluctuations (see e.g. Greenwood et al. (2000), as well as the changes in the skill premium (see e.g. Krusell et al. (2000), Lindquist (2004), and Pourpourides (2011)). The stochastic process for investmentspecific technology, $\tilde{A}_{t}^{k}$ is:

$$
\widetilde{A}_{t+1}^{k}=\left(\widetilde{A}^{k}\right)^{1-\rho_{A^{k}}}\left(\widetilde{A}_{t}^{k}\right)^{\rho_{A^{k}}} e^{\varepsilon_{t+1}^{A^{k}}}
$$

where $\widetilde{A}^{k}>0 ; 0<\rho_{A^{k}}<1$; and $\varepsilon_{t+1}^{A^{k}} \sim i i d N\left[0,\left(\sigma_{A^{k}}\right)^{2}\right]$.

\footnotetext{
${ }^{6}$ Note that in both specifications examined, labour productivity is increasing and concave with respect to employment and bounded between zero and $\Omega^{i}$, where $i=s, u$.
} 
By using equation (14) and defining as $A_{t}^{k} \equiv \frac{1}{\tilde{A}_{t}^{k}}$, we can rewrite the budget constraint of household:

$$
\begin{aligned}
& c_{t}+A_{t}^{k} k_{t+1}+b_{t+1}=\widetilde{r}_{t} k_{t}+\pi_{t}+ \\
& +R_{t}^{b} b_{t}+\left(1-\tau_{t}^{s}\right) n^{s} w_{t}^{s} e_{t}^{s} Z_{t}^{s}+\left(1-\tau_{t}^{u}\right) n^{u} w_{t}^{u} e_{t}^{u} Z_{t}^{u}
\end{aligned}
$$

where $\widetilde{r}_{t}=r_{t}-\tau_{t}^{k}\left(r_{t}-\delta\right)+A_{t}^{k}(1-\delta)$, is the net return to physical capital after depreciation and tax. Note that $A_{t}^{k} \equiv \frac{1}{\tilde{A}_{t}^{k}}$ measures the effective price of investment, since $A_{t}^{k}$ units of investment are needed to create one unit of capital in the next period.

Employment for type $i=s, u$ worker evolves according to:

$$
e_{t+1}^{i}=p_{t}^{i} s_{t}^{i}+\left(1-\gamma_{t}^{i}\right) e_{t}^{i}
$$

where $0<\gamma_{t}^{i}<1$ is the rate of job separation for type $i$ labour. The stochastic process for the job separation rate, $\gamma_{t}^{i}$, is:

$$
\gamma_{t+1}^{i}=\left(\gamma^{i}\right)^{1-\rho_{g^{i}}}\left(\gamma_{t}^{i}\right)^{\rho_{g^{i}}} e^{\varepsilon_{t+1}^{g^{i}}}
$$

where $\gamma^{i}>0 ; 0<\rho_{g^{i}}<1$; and $\varepsilon_{t+1}^{g^{i}} \sim \operatorname{iidN}\left[0,\left(\sigma_{g}^{i}\right)^{2}\right]$.

The household's optimization problem is to choose $\left\{c_{t}, k_{t+1}, b_{t+1}\right\}_{t=0}^{\infty}$ to maximise (7) subject to the constraints (3) and (16) taking factor prices $\left\{w_{t}^{s}, w_{t}^{u}, r_{t}, r_{t}^{b}\right\}_{t=0}^{\infty}$; profits $\left\{\pi_{t}\right\}_{t=0}^{\infty}$; the evolution of employment $\left\{e_{t}^{i}\right\}_{t=0}^{\infty}$; the exogenous variables $\left\{A_{t}^{k}, \gamma_{t}^{i}\right\}_{t=0}^{\infty}$; policy variables $\left\{\tau_{t}^{k}, \tau_{t}^{s}, \tau_{t}^{u}\right\}_{t=0}^{\infty}$ and initial conditions for $k_{0}, b_{0}$ as given.

\subsubsection{First-order conditions (FOCs)}

The recursive form of the household's problem is:

$$
\begin{aligned}
& V\left(k_{t}, b_{t}, e_{t}^{s}, e_{t}^{u}\right)=\max _{c_{t}, k_{t+1}, b_{t+1}}\left\{\left(\ln c_{t}-n^{s} \xi e_{t}^{s}-n^{u} \xi e_{t}^{u}\right)+\right. \\
& \left.+\beta E_{t} V\left(k_{t+1}, b_{t+1}, e_{t+1}^{s}, e_{t+1}^{u}\right)\right\}
\end{aligned}
$$

where $V($.$) is the value function. Replacing c_{t}$ making use of the budget constraint (16) gives:

$$
\begin{aligned}
& V\left(k_{t}, b_{t}, e_{t}^{s}, e_{t}^{u}\right)=\max _{k_{t+1}, b_{t+1}}\left[\operatorname { l n } \left[\widetilde{r}_{t} k_{t}-A_{t}^{k} k_{t+1}-b_{t+1}+\pi_{t}+R_{t}^{b} b_{t}+\right.\right. \\
& \left.+\left(1-\tau_{t}^{s}\right) n^{s} w_{t}^{s} e_{t}^{s} Z_{t}^{s}+\left(1-\tau_{t}^{u}\right) n^{u} w_{t}^{u} e_{t}^{u} Z_{t}^{u}\right]-n^{s} \xi e_{t}^{s}-n^{u} \xi e_{t}^{u}+ \\
& \left.+\beta E_{t} V\left(k_{t+1}, b_{t+1}, e_{t+1}^{s}, e_{t+1}^{u}\right)\right] .
\end{aligned}
$$

The envelope condition for capital stock, $k_{t}$ is:

$$
V_{k}\left(k_{t}, b_{t}, e_{t}^{s}, e_{t}^{u}\right)=\frac{\widetilde{r}_{t}}{c_{t}}
$$


and the first order condition for $k_{t+1}$ is:

$$
\beta E_{t} V_{k}\left(k_{t+1}, b_{t+1}, e_{t+1}^{s}, e_{t+1}^{u}\right)=\frac{A_{t}^{k}}{c_{t}}
$$

which equates the discounted expected marginal benefit to the marginal cost of investment.

Finally, substituting the one-period lead of the envelope condition (21) into the first-order condition for capital (22) gives the consumption Euler:

$$
E_{t}\left(\beta \frac{c_{t} \widetilde{r}_{t+1}}{c_{t+1}}\right)=A_{t}^{k}
$$

which shows that the expected, discounted return on investing in capital must equal its price. Note that the return is discounted using the stochastic discount factor $\beta \frac{c_{t}}{c_{t+1}}$. The envelope condition for government bonds, $b_{t}$ is:

$$
V_{b}\left(k_{t}, b_{t}, e_{t}^{s}, e_{t}^{u}\right)=\frac{R_{t}^{b}}{c_{t}}
$$

and the first order condition for $b_{t+1}$ is:

$$
\beta E_{t} V_{b}\left(k_{t+1}, b_{t+1}, e_{t+1}^{s}, e_{t+1}^{u}\right)=\frac{1}{c_{t}} .
$$

Substituting the one-period lead of the envelope condition (24) into the first-order condition for government bonds (25) gives the bonds Euler, which has a similar interpretation as the Euler for capital:

$$
E_{t}\left(\beta \frac{c_{t}\left(1+r_{t+1}^{b}\right)}{c_{t+1}}\right)=1
$$

The FOCs for the household's problem are given by (16), (23) and (26). These determine the paths for $\left\{c_{t}, k_{t+1}, b_{t+1}\right\}_{t=0}^{\infty}$ given exogenous variables $\left\{A_{t}^{k}, \gamma_{t}^{i}\right\}_{t=0}^{\infty}$; policy variables $\left\{\tau_{t}^{k}, \tau_{t}^{s}, \tau_{t}^{u}\right\}_{t=0}^{\infty}$; initial conditions, $\left\{k_{0}, b_{0}\right\}$; and the paths for variables that are exogenous to the household's problem, i.e. those determined at the aggregate level, $\left\{\pi_{t}, r_{t}, r_{t}^{b}, e_{t+1}^{i}\right\}_{t=0}^{\infty}$ and by wage bargaining, $\left\{w_{t}^{i}\right\}_{t=0}^{\infty}$.

\subsection{Firms}

There is a representative firm which leases capital from the household and employs skilled and unskilled workers to produce a single good, with the objective of maximising profits. 


\subsubsection{Problem}

To hire workers, the firm needs to post vacancies one period before the jobs are required. In particular, the evolution of the number of workers per skilled type employed by the firm is given by the job transition function which links the future number of filled jobs, $l_{t+1}^{f, i}$, to the net hiring, $q_{t}^{i} v_{t}^{i}$, plus the current stock of filled jobs, $\left(1-\gamma_{t}^{i}\right) l_{t}^{f, i}$ :

$$
l_{t+1}^{f, i}=q_{t}^{i} v_{t}^{i}+\left(1-\gamma_{t}^{i}\right) l_{t}^{f, i} .
$$

Given that posting vacancies is costly, the profit function of the firm is:

$$
\pi_{t}^{f}=y_{t}^{f}-r_{t} k_{t}^{f}-w_{t}^{s} l_{t}^{f, s}-\left(1-\tau_{t}^{v, s}\right) \varphi^{s} v_{t}^{s}-w_{t}^{u} l_{t}^{f, u}-\left(1-\tau_{t}^{v, u}\right) \varphi^{u} v_{t}^{u}
$$

where $\varphi^{s}, \varphi^{u}>0$ stand for the constant resource costs of opening a new skilled and unskilled vacancy respectively; and $\tau_{t}^{v, i}$ refer to the vacancy subsidies.

The employment evolution equations in (27) imply that profit maximisation is intertemporal, since expenditure on posting vacancies today will increase profits tomorrow. Therefore, the objective of the firm at time period $t=0$ is to maximise the present value of its lifetime profits, which is given by:

$$
\begin{aligned}
& y_{0}^{f}-r_{0} k_{0}^{f}-w_{0}^{s} l_{0}^{f, s}-\left(1-\tau_{0}^{v, s}\right) \varphi^{s} v_{0}^{s}-w_{0}^{u} l_{0}^{f, u}-\left(1-\tau_{0}^{v, u}\right) \varphi^{u} v_{0}^{u}+ \\
& +E_{t} \sum_{t=1}^{\infty} \prod_{i=1}^{t} \widetilde{r}_{i}^{-1}\left\{y_{t}^{f}-r_{t} k_{t}^{f}-w_{t}^{s} l_{t}^{f, s}-\left(1-\tau_{t}^{v, s}\right) \varphi^{s} v_{t}^{s}-w_{t}^{u} l_{t}^{f, u}-\right. \\
& \left.-\left(1-\tau_{t}^{v, u}\right) \varphi^{u} v_{t}^{u}\right\}
\end{aligned}
$$

where $y_{0}^{f}$ and $y_{t}^{f}$ are given by the CES production function in (1) at time 0 and $t$ respectively.

Since profits are returned to the household, $t+1$ returns are converted to present value terms by the stochastic discount factor from the household's optimisation problem, (23). For $i=s, u$, the firm chooses $\left\{k_{t}^{f}, v_{t}^{i}, l_{t+1}^{f, i}\right\}_{t=0}^{\infty}$ to maximise (29) subject to (27), taking factor prices $\left\{w_{t}^{i}, r_{t}\right\}_{t=0}^{\infty}$; matching probabilities $\left\{q_{t}^{i}\right\}_{t=0}^{\infty}$; exogenous job separation rates $\left\{\gamma_{t}^{i}\right\}_{t=0}^{\infty}$; economic policy $\left\{\tau_{t}^{v, i}\right\}_{t=0}^{\infty}$; and initial conditions for $\left\{l_{0}^{f, i}\right\}$ as given. The variable, $A_{t}$ is determined by the following stochastic process:

$$
A_{t+1}=(A)^{1-\rho_{A}}\left(A_{t}\right)^{\rho_{A}} e^{\varepsilon_{t+1}^{A}}
$$

where $A>0 ; 0<\rho_{A}<1$; and $\varepsilon_{t+1}^{A} \sim i i d N\left[0,\left(\sigma_{A}\right)^{2}\right]$. 


\subsubsection{First-order conditions}

The firm's problem is written in recursive form as:

$$
\begin{aligned}
& J\left(l_{t}^{f, s}, l_{t}^{f, u}\right)=\max _{k_{t}^{f}, v_{t}^{s}, v_{t}^{u}}\left[y_{t}^{f}-r_{t} k_{t}^{f}-w_{t}^{s} l_{t}^{f, s}-\left(1-\tau_{t}^{v, s}\right) \varphi^{s} v_{t}^{s}-\right. \\
& \left.-w_{t}^{u} l_{t}^{f, u}-\left(1-\tau_{t}^{v, u}\right) \varphi^{u} v_{t}^{u}\right]+E_{t} \widetilde{r}_{t+1}^{-1} J\left(q_{t}^{s} v_{t}^{s}+\right. \\
& \left.+\left(1-\gamma_{t}^{s}\right) l_{t}^{f, s}, q_{t}^{u} v_{t}^{u}+\left(1-\gamma_{t}^{u}\right) l_{t}^{f, u}\right)
\end{aligned}
$$

where $J($.$) is the value function. The FOCs for k_{t}^{f}, v_{t}^{s}$ and $v_{t}^{u}$ are:

$$
\begin{gathered}
r_{t}=\frac{1}{\alpha} A_{t}\left\{\theta\left(l_{t}^{f, u}\right)^{\alpha}+(1-\theta)\left[\rho\left(k_{t}^{f}\right)^{\nu}+(1-\rho)\left(l_{t}^{f, s}\right)^{\nu}\right]^{\frac{\alpha}{\nu}}\right\}^{\frac{1}{\alpha}-1} \times \\
\times(1-\theta) \frac{\alpha}{\nu}\left[\rho\left(k_{t}^{f}\right)^{\nu}+(1-\rho)\left(l_{t}^{f, s}\right)^{\nu}\right]^{\frac{\alpha}{\nu}-1} \rho \nu\left(k_{t}^{f}\right)^{\nu-1} \equiv m p l_{t}^{k} \\
\left(1-\tau_{t}^{v, s}\right) \varphi^{s}=E_{t} \widetilde{r}_{t+1}^{-1} q_{t}^{s} J_{l f, s}\left(l_{t+1}^{f, s}, l_{t+1}^{f, u}\right) \\
\left(1-\tau_{t}^{v, u}\right) \varphi^{u}=E_{t} \widetilde{r}_{t+1}^{-1} q_{t}^{u} J_{l^{f, u}}\left(l_{t+1}^{f, s}, l_{t+1}^{f, u}\right)
\end{gathered}
$$

stating respectively that the marginal cost of capital is equal to its marginal benefit and that the marginal costs of creating skilled and unskilled vacancies are equal to the expected return of hiring one additional skilled and unskilled worker next period.

The envelope condition for skilled employment, $l_{t}^{f, s}$ is:

$$
J_{l^{f, s}}\left(l_{t}^{f, s}, l_{t}^{f, u}\right)=m p l_{t}^{s}-w_{t}^{s}+\left(1-\gamma_{t}^{s}\right) E_{t} \widetilde{r}_{t+1}^{-1} J_{l^{f, s}}\left(l_{t+1}^{f, s}, l_{t+1}^{f, u}\right)
$$

where $m p l_{t}^{s}=A_{t}\left\{\theta\left(l_{t}^{f, u}\right)^{\alpha}+(1-\theta)\left[\rho\left(k_{t}^{f}\right)^{\nu}+(1-\rho)\left(l_{t}^{f, s}\right)^{\nu}\right]^{\frac{\alpha}{\nu}}\right\}^{\frac{1}{\alpha}-1} \times$ $\times(1-\theta)\left[\rho\left(k_{t}^{f}\right)^{\nu}+(1-\rho)\left(l_{t}^{f, s}\right)^{\nu}\right]^{\frac{\alpha}{\nu}-1}(1-\rho)\left(l_{t}^{f, s}\right)^{\nu-1}$. After substituting for the continuation value, $\widetilde{r}_{t+1}^{-1} J_{l^{f, s}}\left(l_{t+1}^{f, s}, l_{t+1}^{f, u}\right)$, using the first-order condition for $v_{t}^{s}$ in (33) this condition becomes:

$$
J_{l^{f, s}}\left(l_{t}^{f, s}, l_{t}^{f, u}\right)=m p l_{t}^{s}-w_{t}^{s}+\left(1-\gamma_{t}^{s}\right) \frac{\varphi^{s}}{q_{t}^{s}}\left(1-\tau_{t}^{v, s}\right) .
$$

Finally, to obtain the FOC for the firm, we first lead (36) by one period and substitute it into (33) to obtain:

$$
\left(1-\tau_{t}^{v, s}\right) \frac{\varphi^{s}}{q_{t}^{s}}=E_{t} \widetilde{r}_{t+1}^{-1}\left[m p l_{t+1}^{s}-w_{t+1}^{s}+\left(1-\gamma_{t+1}^{s}\right) \frac{\varphi^{s}}{q_{t+1}^{s}}\left(1-\tau_{t+1}^{v, s}\right)\right]
$$


Working, similarly for unskilled employment, we have:

$$
\left(1-\tau_{t}^{v, u}\right) \frac{\varphi^{u}}{q_{t}^{u}}=E_{t} \widetilde{r}_{t+1}^{-1}\left[m p l_{t+1}^{u}-w_{t+1}^{u}+\left(1-\gamma_{t+1}^{u}\right) \frac{\varphi^{u}}{q_{t+1}^{u}}\left(1-\tau_{t+1}^{v, u}\right)\right] .
$$

where $m p l_{t}^{u}=A_{t}\left\{\theta\left(l_{t}^{f, u}\right)^{\alpha}+(1-\theta)\left[\rho\left(k_{t}^{f}\right)^{\nu}+(1-\rho)\left(l_{t}^{f, s}\right)^{\nu}\right]^{\frac{\alpha}{\nu}}\right\}^{\frac{1}{\alpha}-1} \times$ $\times \theta\left(l_{t}^{f, u}\right)^{\alpha-1}$. These conditions equate the marginal cost of posting a job vacancy to the expected discounted marginal benefit for skilled and unskilled jobs respectively. The benefit is comprised of two elements. First, the increase in profits associated with hiring an extra worker, $m p l_{t+1}^{u}-w_{t+1}^{u}$, and the saving associated with not having to post a job vacancy in the next period, $\left(1-\gamma_{t+1}^{u}\right) \frac{\varphi^{u}}{q_{t+1}^{u}}$.

For $i=s, u$, the FOCs for the firm's problem are given by (27), (28), (32), (37) and (38), which determine the paths for $\left\{l_{t+1}^{f, i}, \pi_{t}^{f}, k_{t}^{f}, v_{t}^{i}\right\}_{t=0}^{\infty}$, given exogenous processes, $\left\{A_{t}, \gamma_{t}^{i}\right\}_{t=0}^{\infty}$; variables that are determined at the aggregate level, $\left\{r_{t}, q_{t}^{i}\right\}_{t=0}^{\infty}$, or by wage bargaining $\left\{w_{t}^{i}\right\}_{t=0}^{\infty}$; and initial conditions for $\left\{l_{0}^{f, i}\right\}$.

\subsection{Wage Bargaining}

We assume that once a worker/household member is matched with a firm, the household and the firm bargain over the wage rate. The equilibrium wage is determined by a Nash bargain. In particular, the equilibrium wage rate maximises the Nash product:

$$
\left[\widetilde{V}_{e^{i}}\left(\widetilde{w}_{t}^{i}\right)\right]^{\phi^{i}}\left[\widetilde{J}_{l f, i}\left(\widetilde{w}_{t}^{i}\right)\right]^{1-\phi^{i}}
$$

where $\phi^{i}$ measures the power of the household/worker relative to the firm in the Nash bargain; $\widetilde{V}_{e^{i}}\left(\widetilde{w}_{t}^{i}\right)$ is the value of a successful bargain at wage $\widetilde{w}_{t}^{i}$ for the household and $\widetilde{J}_{l f, i}\left(\widetilde{w}_{t}^{i}\right)$ is the value of a successful bargain at wage $\widetilde{w}_{t}^{i}$ for the firm.

\subsubsection{Household's valuation of employment}

The valuation of the household for an additional member being employed at wage $w_{t}^{i}$ is given by the envelope conditions of (20) for $e_{t}^{s}$ and $e_{t}^{u}$ respectively:

$$
\begin{aligned}
& V_{e^{s}}\left(k_{t}, b_{t}, e_{t}^{s}, e_{t}^{u}\right)=\frac{\left(1-\tau_{t}^{s}\right) n^{s} w_{t}^{s} Z_{t}^{s}}{c_{t}}-n^{s} \xi+\left(1-\gamma_{t}^{s}-p_{t}^{s}\right) \times \\
& \times \beta E_{t} V_{e^{s}}\left(k_{t+1}, b_{t+1}, e_{t+1}^{s}, e_{t+1}^{u}\right)
\end{aligned}
$$




$$
\begin{aligned}
& V_{e^{u}}\left(k_{t}, b_{t}, e_{t}^{s}, e_{t}^{u}\right)=\frac{\left(1-\tau_{t}^{u}\right) n^{u} w_{t}^{u} Z_{t}^{u}}{c_{t}}-n^{u} \xi+\left(1-\gamma_{t}^{u}-p_{t}^{u}\right) \times \\
& \times \beta E_{t} V_{e^{u}}\left(k_{t+1}, b_{t+1}, e_{t+1}^{s}, e_{t+1}^{u}\right) .
\end{aligned}
$$

We next consider the marginal value to a household of allowing a small number of its members, $\epsilon_{t}^{s}>0$, to be paid an arbitrary wage, $\widetilde{w}_{t}^{s}$, in period $t$, assuming that the wage reverted to the equilibrium wage $w_{t+1}^{s}$ from next period. In these circumstances the value function of household in equation (20) becomes:

$$
\begin{aligned}
& \widehat{V}\left(\widetilde{w}_{t}^{s}, \epsilon_{t}^{s}\right)=\max _{k_{t+1}, b_{t+1}}\left\{\ln \widetilde{r}_{t} k_{t}-A_{t}^{k} k_{t+1}-b_{t+1}+\pi_{t}+R_{t}^{b} b_{t}+\right. \\
& \left.+\left(1-\tau_{t}^{s}\right) n^{s} w_{t}^{s} e_{t}^{s} Z_{t}^{s}+\left(1-\tau_{t}^{s}\right) n^{s} \widetilde{w}_{t}^{s} \epsilon_{t}^{s} Z_{t}^{s}+\left(1-\tau_{t}^{u}\right) n^{u} w_{t}^{u} e_{t}^{u} Z_{t}^{u}\right)- \\
& \left.-n^{s} \xi\left(e_{t}^{s}+\epsilon_{t}^{s}\right)-n^{u} \xi e_{t}^{u}\right\}+\beta E_{t} V\left\{k_{t+1}, b_{t+1},\left[p_{t}^{s}\left(1-e_{t}^{s}-\epsilon_{t}^{s}\right)+\right.\right. \\
& \left.\left.+\left(1-\gamma_{t}^{s}\right)\left(e_{t}^{s}+\epsilon_{t}^{s}\right)\right],\left[p_{t}^{u}\left(1-e_{t}^{u}\right)+\left(1-\gamma_{t}^{u}\right) e_{t}^{u}\right]\right\}
\end{aligned}
$$

Differentiating $\widehat{V}\left(\widetilde{w}_{t}^{s}, \epsilon_{t}^{s}\right)$ with respect to $\epsilon_{t}^{s}$ and evaluating the derivative at $\epsilon_{t}^{s}=0$ to derive the marginal value of a skilled worker employed at an arbitrary wage, $\widetilde{w}_{t}^{s}$ :

$$
\begin{aligned}
& \widehat{V}_{\epsilon^{s}}\left(\widetilde{w}_{t}^{s}, 0\right)=\frac{\left(1-\tau_{t}^{s}\right) n^{s} \widetilde{w}_{t}^{s} Z_{t}^{s}}{c_{t}}-n^{s} \xi+\left(1-\gamma_{t}^{s}-p_{t}^{s}\right) \times \\
& \times \beta E_{t} V_{e^{s}}\left(k_{t+1}, b_{t+1}, e_{t+1}^{s}, e_{t+1}^{u}\right) .
\end{aligned}
$$

If we combine the expression for $\widetilde{V}_{e^{s}}\left(\widetilde{w}_{t}^{s}\right) \equiv \widehat{V}_{\epsilon^{s}}\left(\widetilde{w}_{t}^{s}, 0\right)$ with the envelope condition for $e_{t}^{s}$ in equation (40) we obtain:

$$
\widetilde{V}_{e^{s}}\left(\widetilde{w}_{t}^{s}\right)=\frac{\left(1-\tau_{t}^{s}\right) n^{s}}{c_{t}}\left(\widetilde{w}_{t}^{s}-w_{t}^{s}\right) Z_{t}^{s}+V_{e^{s}}\left(k_{t}, b_{t}, e_{t}^{s}, e_{t}^{u}\right) .
$$

Equivalently, we can derive the marginal value of an unskilled worker employed at an arbitrary wage, $\widetilde{w}_{t}^{u}$ :

$$
\widetilde{V}_{e^{u}}\left(\widetilde{w}_{t}^{u}\right)=\frac{\left(1-\tau_{t}^{u}\right) n^{u}}{c_{t}}\left(\widetilde{w}_{t}^{u}-w_{t}^{u}\right) Z_{t}^{u}+V_{e^{u}}\left(k_{t}, b_{t}, e_{t}^{s}, e_{t}^{u}\right) .
$$

\subsubsection{Firm's valuation of employment}

We work similarly to obtain the firm's valuation of agreeing to employment at a wage $\widetilde{w}_{t}^{i}$. Assume that the firm pays a small fraction, $\psi_{t}^{s}>0$, of employed workers an arbitrary wage $\widetilde{w}_{t}^{s}$ at time period $t$, and that the wage rate will return to the equilibrium wage $w_{t+1}^{s}$ from the next period. The value function of firm, (31) can be modified to:

$$
\begin{aligned}
& \widehat{J}\left(\widetilde{w}_{t}^{s}, \psi_{t}^{s}\right)=\max _{v_{t}^{s}, v_{t}^{u}}\left\{y_{t}^{f}-r_{t} k_{t}^{f}-\left(w_{t}^{s} l_{t}^{f, s}+\widetilde{w}_{t}^{s} \psi_{t}^{s}\right)-\left(1-\tau_{t}^{v, s}\right) \times\right. \\
& \times \varphi^{s} v_{t}^{s}-w_{t}^{u} l_{t}^{f, u}-\left(1-\tau_{t}^{v, u}\right) \varphi^{u} v_{t}^{u}+E_{t} \widetilde{r}_{t+1}^{-1} J\left(\left[q_{t}^{s} v_{t}^{s}+\left(1-\gamma_{t}^{s}\right) \times\right.\right. \\
& \left.\left.\left.\times\left(l_{t}^{s, f}+\psi_{t}^{s}\right)\right],\left[q_{t}^{u} v_{t}^{u}+\left(1-\gamma_{t}^{u}\right) l_{t}^{f, u}\right]\right)\right\} .
\end{aligned}
$$


We differentiate $\widehat{J}\left(\widetilde{w}_{t}^{s}, \psi_{t}^{s}\right)$ with respect to $\psi_{t}^{s}$ and evaluate it at $\psi_{t}^{s}=0$ to get the marginal profit of employing a skilled worker at $\widetilde{w}_{t}^{s}$ :

$$
\begin{aligned}
& \widehat{J}_{\psi^{s}}\left(\widetilde{w}_{t}^{s}, 0\right)=A_{t}\left\{\theta\left(l_{t}^{f, u}\right)^{\alpha}+(1-\theta)\left[\rho\left(k_{t}^{f}\right)^{\nu}+(1-\rho) \times\right.\right. \\
& \left.\left.\times\left(l_{t}^{f, s}\right)^{\nu}\right]^{\frac{\alpha}{\nu}}\right\}^{\frac{1}{\alpha}-1}(1-\theta)\left[\rho\left(k_{t}^{f}\right)^{\nu}+(1-\rho)\left(l_{t}^{f, s}\right)^{\nu}\right]^{\frac{\alpha}{\nu}-1} \times \\
& \times(1-\rho)\left(l_{t}^{f, s}\right)^{\nu-1}-\widetilde{w}_{t}^{s}+\left(1-\gamma_{t}^{s}\right) E_{t} \widetilde{r}_{t+1}^{-1} J_{l f, s}\left(l_{t+1}^{f, s}, l_{t+1}^{f, u}\right) .
\end{aligned}
$$

We then combine this with the envelope condition for $l_{t}^{f, s}$ in (36) to get the marginal profit of employing a skilled worker at an arbitrary wage, $\widetilde{w}_{t}^{s}$, at time $t$, and the equilibrium wage thereafter:

$$
\widetilde{J}_{l^{f, s}}\left(\widetilde{w}_{t}^{s}\right)=w_{t}^{s}-\widetilde{w}_{t}^{s}+J_{l^{f, s}}\left(l_{t}^{f, s}, l_{t}^{f, u}\right)
$$

where $\widetilde{J}_{l^{f, s}}\left(\widetilde{w}_{t}^{s}\right) \equiv \widehat{J}_{\psi^{s}}\left(\widetilde{w}_{t}^{s}, 0\right)$.

Similarly, we can derive the respective condition for unskilled workers:

$$
\widetilde{J}_{l^{f, u}}\left(\widetilde{w}_{t}^{u}\right)=w_{t}^{u}-\widetilde{w}_{t}^{u}+J_{l^{f, u}}\left(l_{t}^{f, s}, l_{t}^{f, u}\right) .
$$

\subsection{3 (Nash) equilibrium wage}

The first-order condition of the Nash bargain (39) with respect to $\widetilde{w}_{t}^{s}$ is:

$$
\begin{aligned}
& 0=\phi^{s}\left[\widetilde{V}_{e^{s}}\left(\widetilde{w}_{t}^{s}\right)\right]^{\phi^{s}-1}\left[\widetilde{J}_{l f, s}\left(\widetilde{w}_{t}^{s}\right)\right]^{1-\phi^{s}} \frac{\partial \widetilde{V}_{e^{s}}\left(\widetilde{w}_{t}^{s}\right)}{\partial \widetilde{w}_{t}^{s}}+ \\
& +\left(1-\phi^{s}\right)\left[\widetilde{V}_{e^{s}}\left(\widetilde{w}_{t}^{s}\right)\right]^{\phi^{s}}\left[\widetilde{J}_{l_{t}^{f, s}}\left(\widetilde{w}_{t}^{s}\right)\right]^{-\phi^{s}} \frac{\partial \widetilde{l}_{t}^{f, s}\left(\widetilde{w}_{t}^{s}\right)}{\partial \widetilde{w}_{t}^{s}} .
\end{aligned}
$$

Substituting the derivatives of (44) and (48) with respect to $\widetilde{w}_{t}^{s}$ as well as the expressions for $\widetilde{V}_{e^{s}}\left(\widetilde{w}_{t}^{s}\right)$ and $\widetilde{J}_{l f, s}\left(\widetilde{w}_{t}^{s}\right)$ from (44) and (48) respectively into (50) and evaluating at $w_{t}^{s}=\widetilde{w}_{t}^{s}$ gives:

$$
\phi^{s} \frac{\left(1-\tau_{t}^{s}\right) n^{s}}{c_{t}} J_{l^{f, s}}\left(l_{t}^{f, s}, l_{t}^{f, u}\right) Z_{t}^{s}=\left(1-\phi^{s}\right) V_{e^{s}}\left(k_{t}, b_{t}, e_{t}^{s}, e_{t}^{u}\right) .
$$

Working as described in detail in Appendix A, we can derive the wage equations (A3) - (A4), which can alternatively be written as:

$$
\begin{aligned}
& \left(1-\tau_{t}^{s}\right) Z_{t}^{s} w_{t}^{s}=\phi^{s}\left\{\left(1-\tau_{t}^{s}\right) Z_{t}^{s}\left[m p l_{t}^{s}+\left(1-\gamma_{t}^{s}\right) \frac{\varphi^{s}}{q_{t}^{s}}\left(1-\tau_{t}^{v, s}\right)\right]-\right. \\
& \left.-\left(1-\gamma_{t}^{s}-p_{t}^{s}\right) E_{t}\left(1-\tau_{t+1}^{s}\right) Z_{t+1}^{s} A_{t}^{k} \frac{\varphi^{s}}{q_{t}^{s}}\left(1-\tau_{t}^{v, s}\right)\right\}+\left(1-\phi^{s}\right) \xi c_{t} .
\end{aligned}
$$




$$
\begin{aligned}
& \left(1-\tau_{t}^{u}\right) Z_{t}^{u} w_{t}^{u}=\phi^{u}\left\{\left(1-\tau_{t}^{u}\right) Z_{t}^{u}\left[m p l_{t}^{u}+\left(1-\gamma_{t}^{u}\right) \frac{\varphi^{u}}{q_{t}^{u}}\left(1-\tau_{t}^{v, u}\right)\right]-\right. \\
& \left.-\left(1-\gamma_{t}^{u}-p_{t}^{u}\right) E_{t}\left(1-\tau_{t+1}^{u}\right) Z_{t+1}^{u} A_{t}^{k} \frac{\varphi^{u}}{q_{t}^{u}}\left(1-\tau_{t}^{v, u}\right)\right\}+\left(1-\phi^{u}\right) \xi c_{t}
\end{aligned}
$$

These equations are generalisations of wage equations under Nash bargaining obtained in the literature (see e.g. Shimer (2010)). For $i=s, u$, the return of an additional worker to the household is given by $\left(1-\tau_{t}^{i}\right) Z_{t}^{i} w_{t}^{i}$, i.e. the after-tax effective (or productivity-adjusted) wage. In equilibrium, this is equal to a weighted average of the effective marginal product of labour under search and matching, i.e. $\left(1-\tau_{t}^{i}\right) Z_{t}^{i}\left[m p l_{t}^{i}+\left(1-\gamma_{t}^{i}\right) \frac{\varphi^{i}}{q_{t}^{i}}\left(1-\tau_{t}^{v, i}\right)\right]-$ $\left(1-\gamma_{t}^{i}-p_{t}^{i}\right) E_{t}\left(1-\tau_{t+1}^{i}\right) Z_{t+1}^{i} A_{t}^{k} \frac{\varphi^{i}}{q_{t}^{i}}\left(1-\tau_{t}^{v, i}\right)$, and the marginal rate of substitution between consumption and leisure, $M R S^{i}$, i.e. $\xi c_{t}$, with the weights given by the bargaining power of the worker. The $M R S^{i}$ follows the common definition of the ratio of the marginal utility of leisure, $\xi$, over the marginal utility of consumption, $1 / c_{t}$. The effective marginal product of labour measures the additional after-tax productivity-adjusted output generated by moving a worker from unemployment to employment. It is comprised of (i) the direct after-tax increase in output provided by an additional skilled worker, $m p l_{t}^{i}$; (ii) the additional savings in terms of resources that would be required to post a vacancy if the matched job survives, $\left(1-\gamma_{t}^{i}\right) \frac{\varphi^{i}}{q_{t}^{i}}\left(1-\tau_{t}^{v, i}\right)$, where $\left(1-\gamma_{t}^{i}\right)$ is the probability that a worker will remain in place in the next period and $\frac{\varphi^{i}}{q_{t}^{i}}\left(1-\tau_{t}^{v, i}\right)$ is the cost per job posting multiplied by the duration that the job needs to be posted, $\frac{1}{q_{t}^{i}} ;^{7}$ (iii) the increase in job-posting costs for the firm implied by the decrease in future successful matches due to the increase in employment, $\left(1-\gamma_{t}^{i}-p_{t}^{i}\right) E_{t}\left(1-\tau_{t+1}^{i}\right) Z_{t+1}^{i} A_{t}^{k} \frac{\varphi}{i}_{t}^{i}\left(1-\tau_{t}^{v, i}\right)$. Note that an increase in current employment increases future unemployment (and thus the requirement for the firm to post a vacancy to fill the lost job) by $\frac{\partial s_{t+1}}{\partial e_{t}}=\left(1-\gamma_{t}^{i}-p_{t}^{i}\right)$, because there is reduction in the number of workers who search for jobs. Furthermore, note that these costs need to be discounted by the price of transferring resources between periods, $A_{t}^{k}$, which equals, from (23), expected future returns to investment discounted by the stochastic discount factor.

The above wage equations hold when there is no $O J L$ and under purely external $O J L$. If we employ the alternative $O J L$ mechanism which internalises own employment on labour productivity, the right hand side of the

\footnotetext{
${ }^{7}$ Note that from $(37)-(38), \frac{\varphi^{i}}{q_{t}^{i}}\left(1-\tau_{t}^{v, i}\right)$ is also equal to the expected benefit to the firm from posting a job.
} 
above equations respectively are multiplied by the term:

$$
\left[\phi^{i}+\frac{\left(1-\phi^{i}\right)\left(Z_{t}^{i}+e_{t}^{i} \frac{\partial Z_{t}^{i}}{\partial e_{t}^{i}}\right)}{Z_{t}^{i}}\right]^{-1}, \quad i=s, u
$$

where $\frac{\partial Z_{t}^{s}}{\partial e_{t}^{s}}=\zeta^{s} \Omega^{s}\left(e_{t}^{s}\right)^{\zeta^{s-1}}\left(\bar{e}_{t}^{u}\right)^{1-\zeta^{s}}$; and $\frac{\partial Z_{t}^{u}}{\partial e_{t}^{u}}=\left(1-\zeta^{u}\right) \Omega^{u}\left(\bar{e}_{t}^{s}\right)^{\zeta^{u}}\left(e_{t}^{u}\right)$. These extra terms: (i) collapse to unity under external $O J L$, i.e. when $\frac{\partial Z_{t}^{i}}{\partial e_{t}^{i}}=0$; (ii) are less than one, ${ }^{8}$ implying that internalising $O J L$ creates a channel that tends to reduce the Nash bargained wage, relative to the cases of no or external $O J L$. When the workers internalise the effect of employment on their productivity and thus on their returns, they are willing to work for a lower wage rate.

\subsection{Government budget and market clearing}

The government budget constraint is:

$$
\begin{aligned}
& g_{t}+\tau_{t}^{v, s} \varphi^{s} v_{t}^{s}+\tau_{t}^{v, u} \varphi^{u} v_{t}^{u}+R_{t}^{b} b_{t}= \\
& =b_{t+1}+\tau_{t}^{k}\left(r_{t}-\delta\right) k_{t}+\tau_{t}^{s} n^{s} w_{t}^{s} e_{t}^{s} Z_{t}^{s}+\tau_{t}^{u} n^{u} w_{t}^{u} e_{t}^{u} Z_{t}^{u}
\end{aligned}
$$

where $g_{t}$ is the per-capita government consumption.

The capital markets clear when the supply is equal to the demand for capital per capita:

$$
k_{t}=k_{t}^{f} .
$$

In the skilled and unskilled labour markets, the equality of per capita labour supply and demand is given by:

$$
n^{s} e_{t}^{s} Z_{t}^{s}=l_{t}^{f, s}
$$

and

$$
n^{u} e_{t}^{u} Z_{t}^{u}=l_{t}^{f, u}
$$

Moreover, dividends paid to the household must equal profits:

$$
\pi_{t}=\pi_{t}^{f} \text {. }
$$

Finally, in the goods markets, the economy's per capita resource constraint is satisfied:

$$
y_{t}^{f}=c_{t}+A_{t}^{k} k_{t+1}-A_{t}^{k}(1-\delta) k_{t}+g_{t}+\varphi^{s} v_{t}^{s}+\varphi^{u} v_{t}^{u} .
$$

\footnotetext{
${ }^{8}$ To see this, first note that $\widetilde{Z} \equiv \frac{\left(Z_{t}^{i}+e_{t}^{i} \frac{\partial Z_{t}^{i}}{\partial e_{t}^{i}}\right)}{Z_{t}^{i}}>1$, since $e_{t}^{i} \frac{\partial Z_{t}^{i}}{\partial e_{t}^{i}}>0$. Then, note that $\phi^{i}+\left(1-\phi^{i}\right) \widetilde{Z}>1 \Rightarrow \phi^{i}+\widetilde{Z}-\phi^{i} \widetilde{Z}-1>0 \Rightarrow$$$
(\widetilde{Z}-1)-\phi^{i}(\widetilde{Z}-1)>0 \Rightarrow 1>\phi^{i} \text {, which is true. Hence, }\left[\phi^{i}+\left(1-\phi^{i}\right) \widetilde{Z}\right]^{-1}<1 \text {. }
$$ 


\subsection{Decentralized equilibrium}

Given the paths of the exogenous variables $\left\{A_{t}, A_{t}^{k}, \gamma_{t}^{s}, \gamma_{t}^{u}\right\}_{t=0}^{\infty}$ and initial conditions for $\left\{k_{0}, b_{0}, e_{0}^{s}, e_{0}^{u}\right\}$, a decentralized equilibrium is defined as a series of prices, $\left\{w_{t}^{s}, w_{t}^{u}, r_{t}, r_{t}^{b}\right\}_{t=0}^{\infty}$, matching probabilities, $\left\{p_{t}^{s}, p_{t}^{u}, q_{t}^{s}, q_{t}^{u}\right\}_{t=0}^{\infty}$ and allocations, $\left\{c_{t}, \pi_{t}, k_{t+1}, b_{t+1}, e_{t+1}^{s}, e_{t+1}^{u}, \pi_{t}^{f}, k_{t}^{f}, v_{t}^{s}, v_{t}^{u}, l_{t+1}^{f, s}, l_{t+1}^{f, u}\right\}_{t=0}^{\infty}$, such that (i) households and firms undertake their respective optimization problems, taking aggregate outcomes and economic policy as given, under search and matching in the labour market as outlined above; (ii) wage rates for both types of labour are determined by a Nash bargain for matched household members and firms; (iii) all budget constraints are satisfied; and (iv) all markets clear. Finally note that in equilibrium, we have $\bar{e}_{t}^{s}=e_{t}^{s}$ and $\bar{e}_{t}^{u}=e_{t}^{u}$.

Using Walras' law we drop the household's budget constraint, so that the DE consists of the following equations: (i) the search and vacancy matching probabilities in (5) and (6); (ii) the consumption and bonds Euler equations (23) and (26); (iii) the firm's optimality conditions given by (27) for $(i=s, u)$, (28), (32), (37) and (38); (iv) the wage equations (A3) and (A4); and (v) the market clearing conditions in (55), (56), (57), (58) and (59). ${ }^{9}$

\section{Quantitative implementation}

In the following section we first discuss the model calibration followed by the quantitative predictions of the model regarding the steady-state and near steady-state dynamics. We consider three model variants, depending on the assumptions we make regarding the labour productivity technology, as captured by $Z_{t}^{i}$, for $i=s, u$. In particular, since we want to contextualise the potential importance of $O J L$, we first consider a benchmark case without it, so that $Z_{t}^{i}=\Omega^{i}=1$. We then choose $\Omega^{i}$ in the cases of $O J L$ that we consider (where the employment effects are purely external, $O J L^{x}$, and where the own effect is internalised, $O J L^{n}$ ) so that the level of labour productivity in the steady-state, $Z^{i}$, is the same across all three model variants. This further implies that the models without $O J L$ and $O J L^{x}$ have identical steady-states, whereas $O J L^{n}$ is re-calibrated following the same strategy as the other two models so that its steady-state is effectively the same.

\footnotetext{
${ }^{9}$ Note that when the market clearing conditions (56) and (57) and the matching probabilities in equations (5) and (6) are imposed on the employment evolution equations (17) and (27) the latter become identical. Hence, we drop the employment evolution equations (17) from the household's problem from the DE.
} 


\subsection{Model Calibration}

Table 1 reports the values for the structural parameters of the model based on a quarterly calibration. ${ }^{10}$ The table indicates how each parameter is obtained by referring to various sources. This includes calculations using: (i) the data; (ii) estimates and assumptions from other studies in the literature; and (iii) calibration to target steady-state values for the relevant endogenous variables of the model. As explained above, these refer to the model variants without and with purely external $O J L$. We summarise at the end is this sub-section the changes in parameters required for the $O J L^{n}$ model.

Table 1: Model Parameters

\begin{tabular}{clll}
\hline \hline Parameter & Value & \multicolumn{1}{c}{ Definition } & Source \\
\hline $0<n^{s}<1$ & 0.450 & population share of skilled workers & data \\
$0 \leq \tau^{k}<1$ & 0.360 & tax rate on capital income & estimate \\
$0 \leq \tau^{s}<1$ & 0.350 & tax rate on skilled labour income & estimate \\
$0 \leq \tau^{u}<1$ & 0.250 & tax rate on unskilled labour income & estimate \\
$g>0$ & 0.425 & per-capita government consumption & calibration \\
$0<\beta<1$ & 0.990 & time discount factor & calibration \\
$0 \leq \delta \leq 1$ & 0.022 & depreciation rate of capital stock & calibration \\
$\frac{1}{1-\nu}$ & 0.669 & capital to skilled labour elasticity & estimate \\
$\frac{1}{1-\alpha}$ & 1.669 & capital to unskilled labour elasticity & estimate \\
$0<\theta<1$ & 0.493 & share of composite input to output & calibration \\
$0<\rho<1$ & 0.820 & share of capital to composite input & calibration \\
$\xi>0$ & 0.100 & disutility cost of employment & calibration \\
$0<\gamma^{s}<1$ & 0.028 & skilled job separation rate & calibration \\
$0<\gamma^{u}<1$ & 0.045 & unskilled job separation rate & calibration \\
$0<\eta^{s}<1$ & 0.600 & elasticity of skilled search & assumption \\
$0<\eta^{u}<1$ & 0.500 & elasticity of unskilled search & assumption \\
$0<\phi^{s}<1$ & 0.600 & bargaining power of skilled workers & assumption \\
$0<\phi^{u}<1$ & 0.500 & bargaining power of unskilled workers & assumption \\
$\varphi^{s}>0$ & 0.900 & unit cost of posting skilled job & calibration \\
$\varphi^{u}>0$ & 0.820 & unit cost of posting unskilled job & calibration \\
$0<\tau^{v, s}, \tau^{v, u}<1$ & 0.010 & job vacancy subsidy & assumption \\
$\chi^{s}>0$ & 0.800 & skilled matching efficiency & calibration \\
$\chi^{u}>0$ & 0.600 & unskilled matching efficiency & calibration \\
$0<\zeta^{s}, \zeta^{u}<1$ & 0.500 & elasticity of learning & assumption \\
\hline
\end{tabular}

${ }^{10}$ Note that, where possible, we follow Shimer (2010, see Appendix A) in the choice of time period (1959-2007). Note however, that the sectoral data employed below are only available from 1992:1-2011:4. 


\subsubsection{Population shares, policy, discount and depreciation rates}

We use data from Acemoglu and Autor (2011) for the period (1963-2008) to calculate the population share of skilled workers, $n^{s}=0.45$. Consistent with the range used in the literature, the time discount factor, $\beta=0.99$, is set to give an annual return to capital, net of depreciation, of about $4 \%$. Similarly the depreciation rate, $\delta=0.022$, is calibrated to target a quarterly steady-state capital to output ratio of about 8 which on an annual basis is consistent with a ratio of around 2. Following Uhlig (2010) we set the tax rate on capital income to $36 \%$. Moreover, we choose the two labour income tax rates to be $\tau^{s}=35 \%$ and $\tau^{u}=25 \%$, which imply a weighted average close to the $28 \%$ labour income tax rate used in Uhlig (2010). The level of government spending is set so that the debt to output ratio is 0.63 or in quarterly terms 2.52 (as in Uhlig (2010)).

\subsubsection{Production}

The elasticities of substitution between skilled labour and capital and between unskilled labour and capital have been estimated by Krusell et al. (2000). We use their estimates, so that $\nu=-0.495$ and $\alpha=0.401$. To ensure the skill premium and labour share in income are consistent with the data, $\theta$ and $\rho$ respectively are calibrated to 0.493 and 0.82 (see, e.g. Lindquist (2004), He and Liu (2008), Pourpourides (2011) and He (2012) who use a similar approach to calibrating the production function). The target value for the skill premium of approximately 1.68 is obtained from Acemoglu and Autor (2011) for the period (1963-2008). We measure the labour income share using data from National Income and Product Accounts Table 1.10, 1959-2013, which gives a value of approximately 0.66. Finally, the parameters capturing steady-state TFP and investment-specific technical change, i.e. $A$ and $A^{k}$ are normalised to unity.

\subsubsection{Utility function and job separation rates}

Following Shimer (2010) we set the disutility of employment parameter, $\xi=$ 0.1 , to imply an aggregate unemployment rate of about 5\%. Also note, that Shimer (2005) reports that an average employment exit probability of 0.034. Given this and the assumption that skilled labour has a lower job separation rate (see, e.g. Fallick and Fleischman (2004), Hagedorn et al. (2010), and Pilossoph (2012)) we set the job separation rates, $\gamma^{s}=0.028$ and $\gamma^{u}=0.045$, to approximately match the sectoral unemployment rates of 
$3 \%$ and $7 \%$ respectively. ${ }^{11}$

\subsubsection{New matches and bargaining power}

The values used for the elasticities of new matches with respect to search time, $\eta^{s}=0.6$ and $\eta^{u}=0.5$, are within the range of econometric evidence reported in Petrongolo and Pissarides (2001). To ensure that the Hosios (1990) condition is satisfied we set the relative bargaining power of worker in the skilled and unskilled sectors respectively to $\phi^{s}=0.6$ and $\phi^{u}=0.5$ (see, Cahuc et al. (2006) who find that skilled workers have higher bargaining power).

\subsubsection{Job posting costs and subsidy}

Pissarides (1994), Acemoglu (2001) and Krause and Lubik (2006 and 2010) suggest that the flow cost of posting a vacancy is higher in 'good' jobs. Following these studies, we assume that the job posting for skilled is greater than that for unskilled labour, i.e. $\varphi^{s}>\varphi^{u}$. These parameters are calibrated to ensure aggregate job costs as a share of GDP of about $2.5 \%$ which coheres with Arseneau and Chugh (2012) and aggregate labour market tightness of about unity which is the value used in Pissarides (1998) and Campolmi and Gnocchi (2014). Also following Campolmi et al. (2011) we set the vacancy subsidy rate to $1 \%$.

\subsubsection{Matching efficiency and OJL}

Consistent with an aggregate unemployment rate of $5 \%$ and an average employment exit probability of 0.034, Shimer (2010, see p. 67) implies a job finding probability about 0.65 . Following this approach for each labour market gives us target probabilities of $p^{s}=0.828$ and $p_{t}^{u}=0.591$ which we obtain by calibrating $\chi^{s}=0.8$ and $\chi^{u}=0.6$. The finding probabilities in turn imply unemployment durations of about 1.21 and 1.69 quarters for skilled and unskilled respectively. The calibration also suggests that the job filling rate is higher for the skilled versus the unskilled consistent with Krause and Lubik (2006 and 2010). As explained above, we present the models results below both without and with learning. In the former, $Z_{t}^{s}=Z_{t}^{u}=1$ in (10-11). In both forms of latter (i.e. $O J L^{x}$ and $\left.O J L^{n}\right)$ we set the exponents $\zeta^{s}=\zeta^{u}=0.5$ and calibrate $\Omega^{s}$ and $\Omega^{u}$ so that in the steady-state

\footnotetext{
${ }^{11}$ The sectoral employment and unemployment data are from the monthly Labor Force Statistics, Current Population Survey for period (1992:1-2011:4). It reports data for civilian non-institutional population 25 years and over by educational attainment. Skilled workers are those with a Bachelor's degree and higher.
} 
the $Z$ functions are equal to unity as under no learning. This requires that $\Omega^{s}=\Omega^{u}=1.055 .^{12}$

\subsection{Steady-state}

The steady-state implied by the above calibration is reported in Table 2 for the models without and with purely external learning. These results show that great ratios are well in line with the U.S. data. Moreover, the remaining values cohere with the targets discussed in the calibration above. For the third model variant, the results are quantitatively similar. To ensure that the model under $O J L^{n}$ implies an analogous steady-state with the remaining two model-variants, we re-calibrate $\theta=0.500, \varphi^{s}=1.600, \varphi^{u}=1.520$, and $g=0.401$, following the same calibration strategy outlined above. Note that as discussed in Section 2.6.3, when workers internalise $O J L$, bargained wages tend to be lower and thus unemployment lower. Therefore, to maintain the same level of unemployment and labour market tightness in the steady-state, job-posting costs need to increase.

Table 2: Steady-state

\begin{tabular}{ccccccccc}
\hline \hline$\frac{c}{y}$ & $\frac{k}{y}$ & $\frac{g}{y}$ & $\frac{b}{y}$ & $\frac{w e}{y}$ & $\frac{v}{y}$ & $s^{s}$ & $s^{u}$ & $s$ \\
\hline 0.571 & 8.198 & 0.225 & 2.520 & 0.660 & 0.024 & 0.033 & 0.071 & 0.054 \\
$\frac{w^{s}}{w^{u}}$ & $\widetilde{r}$ & $r^{b}$ & $z^{s}$ & $z^{u}$ & $p^{s}$ & $p^{u}$ & $q^{s}$ & $q^{u}$ \\
1.680 & 0.010 & 0.010 & 1.089 & 0.971 & 0.828 & 0.591 & 0.760 & 0.609 \\
\hline
\end{tabular}

\subsection{Stochastic processes}

When undertaking the model simulations we draw the four processes discussed above from a multivariate normal distribution, denoted $\mathbf{x}=N(\overline{\mathbf{x}}, \boldsymbol{\Sigma}$, where $\mathbf{x}=\left[\varepsilon_{t}^{A}, \varepsilon_{t}^{A^{k}}, \varepsilon_{t}^{g^{s}}, \varepsilon_{t}^{g^{u}}\right], \overline{\mathbf{x}}$ is the vector of means and $\boldsymbol{\Sigma}$ is the variancecovariance matrix of shocks. The parameters of stochastic processes driving the model are reported in Table 3. The autocorrelation parameter of TFP is set equal to 0.95, following Gertler and Trigari (2009), and Arseneau and Chugh (2012). As in the literature, the volatility parameter, $\sigma_{A}$, is calibrated to match the standard deviation of HP-filtered output, 0.011. Re-

\footnotetext{
${ }^{12}$ Given the lack of data for exponents in the learning functions, we experiment with some alternative combinations. For example, we place more weight on the own-elasticity for the skilled, i.e. $\zeta^{s}=0.8$ and $\left(1-\zeta^{s}\right)=0.2$ while at the same time keeping weight of the own-elasticity for the unskilled: (i) the same, $\zeta^{u}=0.5$ and $\left(1-\zeta^{u}\right)=0.5$; (ii) higher, $\zeta^{u}=0.8$ and $\left(1-\zeta^{u}\right)=0.2$; and (iii) lower, $\zeta^{u}=0.2$ and $\left(1-\zeta^{u}\right)=0.8$. We find that the results reported below, including steady-state, second-moments, impulse responses and fiscal multipliers, are robust these to alternative parameterisations. This applies to both the $O J L^{x}$ and $O J L^{n}$ setups.
} 
garding investment-specific technical change, we use the estimates from Pourpourides (2011), which implies setting $\rho_{A^{k}}$, to 0.6015 and $\sigma_{A^{k}}$, to 0.0047 . Given the lack of sectoral data for the job separation rates, we apply the same quarterly autocorrelation, $\rho_{\gamma^{s}}$ and $\rho_{\gamma u}$, and standard deviation, $\sigma_{\gamma^{s}}$ and $\sigma_{\gamma^{u}}$, parameters for skilled and unskilled using data from the Job Openings and Labor Turnover Survey (JOLTS) for the period 2001Q1-2014Q2. Finally, the correlation between job separation shocks, $\operatorname{cor}\left(\varepsilon_{t}^{g^{s}}, \varepsilon_{t}^{g^{u}}\right)$, is calibrated to match the correlation between HP-filtered skilled and unskilled employment/unemployment rates in the data. ${ }^{13}$

Table 3: Stochastic processes

\begin{tabular}{clll}
\hline \hline Parameter & Value & \multicolumn{1}{c}{ Definition } & Source \\
\hline$\sigma_{A}$ & 0.008 & SD of TFP & calibration \\
$\rho_{A}$ & 0.950 & AR(1) coefficient of TFP & assumption \\
$\sigma_{A^{k}}$ & 0.0047 & SD of IT & estimate \\
$\rho_{A^{k}}$ & 0.6015 & AR(1) coefficient of IT & datimate \\
$\sigma_{\gamma^{s}}$ & 0.073 & SD of skilled separation rate & data \\
$\rho_{\gamma^{s}}$ & 0.740 & AR(1) coef. of skilled separation rate & data \\
$\sigma_{\gamma^{u}}$ & 0.073 & SD of unskilled separation rate & data \\
$\rho_{\gamma^{u}}$ & 0.740 & AR(1) coef. of unskilled separation rate & dation \\
$\operatorname{cor}\left(\varepsilon_{t}^{g^{s}}, \varepsilon_{t}^{g^{u}}\right)$ & 0.980 & Job separation rate shock correlation & calibration \\
\hline
\end{tabular}

\subsection{Solution and second moments}

Following Shimer (2010), we present results under shocks to TFP and the job separation rates but we also consider investment-specific technological change, given the importance attached to skill-biased technical change in explaining the behaviour of the skill premium in the literature. The results for the sectoral variables discussed in the Introduction are presented in Table 4. To obtain these results we first solve a first-order approximation of the dynamic system of equations characterising the DE around the steady-state, by implementing the perturbation methods in Schmitt-Grohé and Uribe (2004). We then simulate time paths under shocks to total factor productivity, the job separation rates and investment-specific technological change, as indicated. We conduct 10,000 simulations of 80 periods (i.e. 1992Q1-2011Q4) to match the sectoral employment and unemployment data and 100 periods (i.e. 1979Q1-2003Q4) to match the skill premium data, initialised from the steady-state in Table 2. For each simulation, we HP-filter the logged series and then compute the required moments and report the means of these

${ }^{13}$ Note that not allowing for this correlation only affects this target. 
moments across the simulations in Table 4.

Table 4: Second moments

\begin{tabular}{lccccccc}
\hline \hline & \multicolumn{4}{c}{ Shocks to $A, \gamma^{i}$} & \multicolumn{3}{c}{ Shocks to $A, A^{k}, \gamma^{i}$} \\
& Data & no $O J L$ & $O J L^{x}$ & $O J L^{n}$ & no OJL & $O J L^{x}$ & $O J L^{n}$ \\
\hline$\rho\left(e^{s}, e^{u}\right)$ & 0.961 & 0.960 & 0.960 & 0.961 & 0.960 & 0.960 & 0.961 \\
$\rho\left(e^{s}, y\right)$ & 0.927 & 0.252 & 0.444 & 0.447 & 0.249 & 0.441 & 0.444 \\
$\rho\left(e^{u}, y\right)$ & 0.931 & 0.264 & 0.459 & 0.462 & 0.261 & 0.456 & 0.459 \\
$\rho\left(w^{s} / w^{u}, y\right)$ & 0.086 & 0.078 & -0.179 & -0.217 & 0.073 & -0.149 & -0.168 \\
$\sigma\left(e^{s}\right) / \sigma(y)$ & 0.327 & 0.248 & 0.225 & 0.228 & 0.248 & 0.224 & 0.228 \\
$\sigma\left(e^{u}\right) / \sigma(y)$ & 0.597 & 0.485 & 0.442 & 0.447 & 0.484 & 0.441 & 0.446 \\
$\sigma\left(w^{s} / w^{u}\right) / \sigma(y)$ & 0.870 & 0.208 & 0.248 & 0.347 & 0.256 & 0.283 & 0.433 \\
\hline
\end{tabular}

As can be seen in Table 4, all three model variants predict sectoral labour market quantities that have qualitatively similar cyclical properties with the data. In particular, the model predicts positive correlations between output and employment (although not so strong as in the data) and a very low correlation between output and the skill premium. It is notable that the output correlations of employment are very low without $O J L$, but increase and are qualitatively closer to the data under $O J L$. Furthermore, the models predict a standard deviation for de-trended skill premium and output that is lower than that of output, consistent with the data. Quantitatively, the volatility of the skill premium is improved when shocks to $A^{k}$ are included in the set of exogenous processes.

All models under-predict, quantitatively, the volatility of employment in the two sectors, which is expected given the results in Shimer (2005 and 2010). However, the predicted volatility of employment in the sectoral model is significantly improved compared with the canonical one-sector model. In particular, the model variants predict an employment volatility which ranges from $69 \%$ to $81 \%$ of the volatility of employment in the data, whereas in the canonical models in e.g. Shimer (2010), this ratio is typically about $25 \% .^{14}$ Moreover, the models do capture a key property of sectoral employment, in particular that unskilled employment is nearly twice as volatile as skilled employment.

These model-generated second moments match the characteristics of sectoral employment and wage inequality that were discussed in the Introduction. The results in Table 4 further suggest that it is not easy to distinguish the model variants based on their ability to fit the sectoral second moments. While qualitatively they are all similar, each model has relative

\footnotetext{
${ }^{14}$ Shimer (2010, p. 95) describes standard deviations of employment relative to output of a magnitude of about $45 \%$, to "finally generate interesting fluctuations in employment".
} 
successes compared with the others. However, the models with $O J L$ are clearly preferable to the model that does not allow for $O J L$ regarding the output correlations for employment. Therefore, to analyse the effect of policy below we present results for all three model variants. This allows us to provide a range for the likely size of the fiscal multipliers arising from targeted labour market interventions and thus to quantitatively evaluate the importance of $O J L$ or skill erosion for the effects of policy interventions.

\section{Fiscal interventions in the labour market}

We next consider the effect of targeted labour market policies in the form of job-posting subsidies and income tax cuts. ${ }^{15}$ In particular, we focus the following policy experiments. First, that the government increases $\tau_{t}^{v, s}$ temporarily by one percentage point and lets government debt absorb the fiscal implications of the shock. Second, we examine the effects of a similar increase in $\tau_{t}^{v, s}$ under fixed government debt, so that the policy intervention is financed by a proportional increase in the labour and capital income tax rates. ${ }^{16}$ This budgetary restriction is particularly relevant given the current, post financial crisis economic reality that severely limits the use of debt to finance fiscal interventions in most advanced economies. We then repeat the same experiments for an increase in $\tau_{t}^{v, u}$ by one percentage point. Finally, we discuss the implications of labour market interventions in the form of cuts in the labour income taxes by one-percentage point. ${ }^{17}$ To implement the above experiments, we assume that when temporarily shocked, vacancy subsidies and income taxes follow standard $\mathrm{AR}(1)$ processes. $^{18}$

We first discuss the impulse responses of the first policy experiment in detail, to analyse the channels via which vacancy subsidies affect employment in the two sectors and output. We focus on the two models that have the same calibration and steady-state, i.e. without $O J L$ and under $O J L^{x}$, since

\footnotetext{
${ }^{15}$ See Campolimi et al. (2011) and Faia et al. (2013) who conduct similar analysis in the context of a search and matching model with endogenous participation and a labour selection model with turnover costs and Nash bargained wages, respectively.

${ }^{16}$ In this case, we fix the level of government debt to its steady-state level, let one of the income taxes to be the residual policy instrument in the government budget constraint, and fix the remaining two income taxes to remain in the same proportion with the residual income tax as in the steady-state.

${ }^{17}$ Note that normalising the tax cuts to have the same fiscal implications as the vacancy subsidy interventions yields effectively the same results.

${ }^{18}$ Following Campolmi et al. (2011) we set the AR(1) parameters for the vacancy subsidies to 0.90 and following Angelopoulos et al. we set the $\operatorname{AR}(1)$ parameters on the skilled and unskilled income taxes to 0.950 and 0.920 .
} 
the effects are directly comparable, and thus we can trace the workings of the $O J L$ mechanism following the policy intervention. We then summarise the implications for output and unemployment in each case by calculating the fiscal multipliers for the remaining labour market interventions that we consider. Following Leeper et al. (2009) we calculate fiscal multipliers as follows:

$$
F M_{k}=\frac{\sum_{j=0}^{k}\left(\prod_{i=0}^{j} R_{t+i}^{-1}\right) \Delta y_{t+j}}{\sum_{j=0}^{k}\left(\prod_{i=0}^{j} R_{t+i}^{-1}\right) \Delta x_{t+j}}
$$

where $R_{t} \equiv 1+\left(1-\tau_{t}^{k}\right)\left(r_{t}-\delta\right) ; \Delta y_{t}=\left(y_{t}-y\right)$ and $\Delta x_{t}=\left(x_{t}-x\right)$. For the vacancy subsidy multipliers $\Delta x_{t}=\widetilde{\tau}_{t}^{v, i}-\widetilde{\tau}^{v, i}$, where $i=s, u$ and $\widetilde{\tau}_{t}^{v, i}=\varphi^{i} v_{t}^{i} \tau_{t}^{v, i}$ gives the cost of the subsidy. Finally for the tax multipliers $\Delta x_{t}=\widetilde{\tau}_{t}^{i}-\widetilde{\tau}^{i}$, where $\widetilde{\tau}_{t}^{i}=n^{i} \tau_{t}^{i} w_{t}^{i} e_{t}^{i}$ (without $O J L$ ) and $\widetilde{\tau}_{t}^{i}=n^{i} \tau_{t}^{i} w_{t}^{i} e_{t}^{i} Z_{t}^{i}$ (under $O J L^{x}$ and $\left.O J L^{n}\right)$ represent the respective costs of the tax reduction.

\subsection{Impulse responses to $\tau_{t}^{v, s}$}

In Figure 2 we present the impulse response functions of a temporary increase in $\tau_{t}^{v, s}$ by one percentage point under flexible debt. The main results from an increase in the subsidy to the vacancy posting costs for skilled workers is that employment for skilled workers increases along with their wages and the skill premium, while, at the aggregate level, investment and output increase. However, the magnitudes of these aggregate effects depend on the assumptions regarding on-the-job learning, which is also critical in determining the effects of this policy on aggregate consumption and the unskilled labour market.

[Figure 2 here]

An increase in $\tau_{t}^{v, s}$ implies that the cost for posting skilled vacancies is reduced, so that the number of vacancies, $v_{t}^{s}$, increases and employment follows. These effects are quantitatively very similar for all model variants irrespective of $O J L$, since job posting decisions of the firm are not directly affected by $O J L$. Wages increase for skilled workers when employment increases, since the workers can bargain for a share of the higher expected firm profits from a successful match under reduced unemployment. Note that both $p_{t}^{s}$ and $1 / q_{t}^{s}$ increase when unemployment is reduced (and/or vacancies increase), so that from (52) $w_{t}^{s}$ increases.

The rise in employment crowds in investment and consumption (at least after some periods without $O J L$ ) for two reasons. First, the marginal product of capital, $m p l^{k}$, has increased, since it is a positive function of employment 
and this tends to increase investment. Second, the income of the household has increased, because of higher employment and wages of skilled, as well as higher profits of the firm. In turn, the increased employment and capital increase output. Under $O J L$, consumption, investment and output increase by more, because the rise in employment has a direct productivity effect on production (and thus the marginal product of capital, output, and household income). Without $O J L$, the household income gains are not strong enough initially to allow the household to increase both consumption and investment, so that it is optimal to reduce consumption to increase investment temporarily.

Increases in skilled job posting vacancies also have an effect on the unskilled labour market. The increase in $e_{t}^{s}$ increases the marginal product of unskilled labour, $m p l^{u}$, which tends to increase labour demand and vacancy postings for unskilled jobs. However, under $O J L$, there are additional effects. In particular, since $e_{t}^{s}$ increases the effective quantity of unskilled labour (by increasing $Z_{t}^{u}$ ), this tends to decrease $m p l^{u}$, which is decreasing in the effective quantity of unskilled labour. Therefore, under $O J L$, there is a channel that tends to mediate the positive effects of $\tau_{t}^{v, s}$ on the unskilled labour market, so that the final effect of $\tau_{t}^{v, s}$ on $e_{t}^{u}$ is bigger without $O J L$. The unskilled wage increases because $m p l^{u}$ has risen. Relative to the effects of $\tau_{t}^{v, s}$ on $w_{t}^{s}$, the positive effects of $\tau_{t}^{v, s}$ on $w_{t}^{u}$ are second order and thus $w_{t}^{u}$ rises by less, so that the skill premium increases.

\subsection{Fiscal multipliers}

We next present and discuss the fiscal multipliers for the different fiscal interventions in the labour markets.

\subsubsection{Skilled vacancy subsidy}

The fiscal multipliers associated with the increase in the subsidy for posting skilled jobs are shown in the first row of Figure 3. As can be seen, the unemployment multipliers are negative and the output multipliers are positive. As expected, given the previous analysis and the impulse responses of employment and output, the FMs: (i) are effectively the same without and with $O J L^{x}$ for skilled unemployment; (ii) are significantly smaller for unskilled unemployment; and (iii) vary significantly between the cases without and with $O J L^{x}$ for output. The magnitude of the skilled unemployment FM reported here is similar to e.g. the unemployment multipliers reported in Monacelli et al. (2010). However, OJ $L^{x}$ introduces a channel that translates standard employment effects to big output multipliers. As explained above, 
in this case the increase in employment crowds in significant investment, as the increase in labour productivity raises the marginal product of capital, as well as household income, to high levels. In fact, under $O J L^{x}$ the output multiplier is greater than one.

[Figure 3 here]

We then repeat the policy intervention of the increase in the subsidy for posting skilled jobs, this time working with the fixed debt restriction, so that the fiscal implications of the increased expenditure are met by increases in income taxation. The fiscal multipliers in this case are reported in the second row on Figure 3. As can be seen, the size of the multipliers is effectively unaffected, suggesting that this type of labour market intervention is potentially very useful in an environment where the ability of the government to use public debt to boost the economy is restricted. Since the fiscal implications of the vacancy subsidy are relatively small, the size of the multipliers is predominantly driven by the change in the target quantities in the numerators of (60), for which the effect of the vacancy subsidy is direct and dominates the side-effects arising from modest increases in income taxation.

\subsubsection{Unskilled vacancy subsidy}

Working as above, we obtain the fiscal multipliers for the increase in the subsidy for posting unskilled jobs. These are shown in Figure 4, under flexible and fixed debt. The effects are generally similar to those under vacancy subsidies to skilled workers, obviously with the main employment effect in this case being in the unskilled labour market. There are some notable differences between increases in $\tau_{t}^{v, s}$ and $\tau_{t}^{v, u}$. First, the size of the unemployment and output multipliers are bigger for $\tau_{t}^{v, u}$, because the unskilled labour market is characterised by higher unemployment, so that the corrective potential for government policy is stronger. Second, the cross-unemployment effect for the $\tau_{t}^{v, u}$ intervention is positive under $O J L^{x}$, although still relatively small compared with the effect on the unemployment of the labour market where the policy is applied. The previous analyses shows that the cross-unemployment effect under $O J L^{x}$ is less favourable because in this case the cross marginal product of labour is negatively affected by the increase in labour productivity of the labour input in the other sector via the $O J L$ channel. In this case, this additional negative effect dominates, so that employment in skill jobs is reduced after an increase in $\tau_{t}^{v, u}$.

[Figure 4 here] 


\subsubsection{Vacancy subsidies under $O L J^{n}$}

In Figure 5, we report the fiscal multipliers for the increase in the subsidies for posting skilled and unskilled jobs, under flexible and fixed debt, when $O J L$ is internalised by the workers. The results are broadly similar to those obtained under $O L J^{x}$ (compare with Figures 3 and 4 above) and thus the multipliers are bigger compared with a labour market without $O J L$, given the positive spill-over effects of $O J L$. Quantitatively, the size of the output and own-employment multipliers is smaller under $O L J^{n}$, compared with $O L J^{x}$. When the labour productivity effects of employment are internalised in the Nash bargain, the workers bargain for a bigger rise in their wage, so that they extract a higher share of the firm's profits, which in turn leads to lower increases in investment. As a result, the employment and output multipliers are smaller. Moreover, the above channel also implies that positive spillover effects on the marginal product of labour and employment for the other worker-type are lower, so that cross-unemployment is increased, although again by a small amount.

[Figure 5 here]

\subsubsection{Income tax cuts}

Finally, we considered one-percentage point cuts in the labour income taxes. While positive, the fiscal multipliers associated with these interventions are significantly smaller compared with the vacancy subsidies. The change in vacancy subsidies, as explained above, is a supply-side effect that works via the firm side, by reducing the cost of creating jobs. Therefore, the employment effects are driven by the creation of new jobs. On the other hand, a reduction in income taxes works via the worker's evaluation of opportunity costs and benefits under employment, and thus affects outcomes via the Nash bargained wage rate. In particular, it lowers the wage rate as a result of Nash bargaining, given that the opportunity cost to work (and thus the outside option) is reduced and this increases employment. Therefore, while vacancy subsidies affect employment directly, by reducing a market friction, income taxes affect unemployment indirectly, by working via the distorted labour market, i.e. Nash bargaining, which implies that part of the benefits are lost. To illustrate these effects, we plot, in Figure 6, the FMs for a reduction in $\tau_{t}^{s}$ and $\tau_{t}^{u}$.

[Figure 6 here] 


\section{Conclusions}

This paper evaluated the effects of policy interventions on sectoral labour markets and the aggregate economy in a business cycle model with search and matching frictions. We extended the canonical model by including capitalskill complementarity in production, skilled and unskilled labour markets and on-the-job-learning (OJL) within and across skill types. Our policy analysis evaluated the effects of temporary interventions in the labour markets and the aggregate economy. We found fiscal multipliers on output from the subsides to skilled and unskilled vacancies, which were greater than unity when $O J L$ was external and near unity when it was internal. These large multipliers were determined by the crowding-in of private investment, which followed the increases in employment and labour productivity. Without $O J L$, the labour productivity channel was absent and caused the output multipliers to fall to about 0.6. In contrast to the vacancy subsidies, the positive output effects from cutting skilled and unskilled income taxes were near zero,irrespective of the presence, or model, of $O J L$. We finally found that the effects of the two vacancy subsidies did not depend on whether debt or distorting taxes were used to finance them. This is particularly good news, and suggests that this type of intervention may be useful under the debt restrictions that many governments now face in the wake of the financial crisis.

\section{References}

[1] Acemoglu, D. (2001). 'Good jobs versus bad jobs', Journal of Labor Economics, 19, 1-21.

[2] Acemoglu, D. and D. Autor (2011). 'Skills, tasks and technologies: implications for employment and earnings', in O. Ashenfelter and D. Card (eds.), Handbook of Labor Economics, 4b, 1043-1171, Amsterdam: Elsevier.

[3] Angelopoulos, K., Asimakopoulos, S. and J. Malley (2013). 'The optimal distribution of the tax burden over the business cycle', CESifo Working Paper Series 4468, CESifo Group Munich.

[4] Arseneau, D. and S. Chugh (2012). 'Tax smoothing in frictional labor markets', Journal of Political Economy, 120, 926-985.

[5] Barro, R. and X. Sala-i-Martin (1994). 'Quality improvements in models of growth', CEPR Discussion Papers 1076. 
[6] Blanchard, O. and P. Diamond (1989). 'The beveridge curve', Brookings Papers on Economic Activity, 1, 1-60.

[7] Cahuc, P., Postel-Vinay, F. and J. Robin (2006). 'Wage bargaining with on-the-job search: theory and evidence', Econometrica, 74, 323-364.

[8] Campolmi, A. and S. Gnocchi (2014). 'Labor market participation, unemployment and monetary Policy', Bank of Canada working paper, 2014-09.

[9] Campolmi A., Faia, E. and R. Winkler (2011). 'Fiscal Calculus and the Labor Market', The B.E. Journal of Macroeconomics, 11, 1-27.

[10] Castro, R. and D. Coen-Pirani (2008). 'Why have aggregate skilled hours become so cyclical since the mid-1980s?', International Economic Review, 49, 135-184.

[11] Davis, S. and T. von Wachter (2011). 'Recessions and the costs of job loss', Brookings Papers on Economic Activity, 43, 1-72.

[12] Dolado, J., Jansen, M. and J. Jimeno (2009). 'On-the-job search in a matching model with heterogeneous jobs and workers', Economic Journal, 119, 200-228.

[13] Doppelt, R. (2014). 'Skill flows: a theory of human capital and unemployment', working paper.

[14] Faia, E., Lechthaler, W. and C. Merkl (2013). 'Fiscal stimulus and labor market policies in Europe', Journal of Economic Dynamics and Control, $37,483-499$

[15] Fallick, B. and C. Fleischman (2004). 'Employer-to-employer flows in the U.S. labor market: the complete picture of gross worker flows', Working Paper 2004-34, Federal Reserve Board of Governors.

[16] Gertler, M. and A. Trigari (2009). 'Unemployment fluctuations with staggered Nash wage bargaining', Journal of Political Economy, 117, $38-86$.

[17] Goldin, C. and L. Katz (2008). The race between education and technology, Harvard University Press.

[18] Greenwood, J., Hercowitz, Z. and P. Krusell (2000). 'The role of investment-specific technological change in the business cycle', European Economic Review, 44, 91-115. 
[19] Hagedorn, M., Manovskii, I. and S. Stetsenko (2010). 'Taxation and unemployment in models with heterogeneous workers', mimeo, University of Pennsylvania.

[20] He, H. and Z. Liu (2008). 'Investment-specific technological change, skill accumulation, and wage inequality', Review of Economic Dynamics, 11, 314-334.

[21] He, H. (2012). 'What Drives the Skill Premium: Technological change or demographic variation?', European Economic Review, 56, 1546-1572.

[22] Hosios, A. (1990). 'On the efficiency of matching and related models of search and unemployment', Review of Economic Studies, 57, 279-298.

[23] Katz, L. and K. Murphy (1992). 'Changes in relative wages, 1963-1987: supply and demand factors', The Quarterly Journal of Economics, 107, 35-78.

[24] Krause, M. and T. Lubik (2006). 'The cyclical upgrading of labour and on-the-job search', Labour Economics, 13, 459-77.

[25] Krause, M. and T. Lubik (2010). 'On-the-job search and the cyclical dynamics of the labor market', Federal Reserve Bank of Richmond Working Paper Series WP, 10-12.

[26] Krusell, P., Ohanian, L., Rİos-Rull J. and G. Violante (2000). 'Capitalskill complementarity and inequality: a macroeconomic analysis', Econometrica, 68, 1029-1053.

[27] Laureys, L. (2014). 'The cost of human capital depreciation during unemployment', Bank of England Working Paper, No. 505.

[28] Leeper, E., Plante, M., and N. Traum (2010). 'Dynamics of fiscal financing in the United States', Journal of Econometrics, 156, 304-321.

[29] Lindquist, M. (2004). 'Capital-skill complementarity and inequality over the business cycle', Review of Economic Dynamics, 7, 519-540.

[30] Merz, M. (1995). 'Search in the labor market and the real business cycle', Journal of Monetary Economics, 36, 269-300.

[31] Monacelli, T., Perotti, R. and A. Trigari (2010). 'Unemployment fiscal multipliers', Journal of Monetary Economics, 57, 531-553. 
[32] Petrongolo, B. and C. Pissarides (2001). 'Looking into the black box: a survey of the matching function', Journal of Economic Literature, 39, $390-431$.

[33] Pilossoph, L. (2012). A multisector equilibrium search model of labor reallocation, Ph.D. thesis, The University of Chicago.

[34] Pissarides, C. (1986). 'Vacancies and unemployment in Britain', Economic Policy, 3, 499-559.

[35] Pissarides, C. (1994). 'Search unemployment with on the job search', Review of Economic Studies 61, 457-476.

[36] Pissarides, C. (1998). 'The impact of employment tax cuts on unemployment and wages: the role of unemployment benefits and tax structure', European Economic Review, 42, 155-183.

[37] Pollak, R. (2013). 'Allocating household time: when does efficiency imply specialization?' NBER Working Papers 19178.

[38] Pourpourides, P. (2011). 'Implicit contracts and the cyclicality of the skill-premium', Journal of Economic Dynamics and Control, 35, 963979.

[39] Rogerson, R. and R. Shimer (2011). 'Search in macroeconomic models of the labor market', Handbook of Labor Economics, Elsevier.

[40] Romer, P. (1996). 'Increasing returns and long-run growth', Journal of Political Economy, 94, 1002-1037.

[41] Schmitt-Grohe, S. and M. Uribe (2004). 'Solving dynamic general equilibrium models using a second-order approximation to the policy function', Journal of Economic Dynamics and Control, 28, 755-775.

[42] Shimer, R. (2005). 'The cyclical behavior of equilibrium unemployment and vacancies', American Economic Review, 95, 25-49.

[43] Shimer, R. (2010). Labor Markets and Business Cycles, CREI Lectures in Macroeconomics, Princeton University Press.

[44] Uhlig, H. (2010). 'Some fiscal calculus', American Economic Review, $100,30-34$. 


\section{Appendix A: Derivation of Wage Equations}

Using (51) and its one-period lead to eliminate $V_{e^{s}}\left(k_{t}, e_{t}^{s}, e_{t}^{u}\right)$ and $V_{e^{s}}\left(k_{t+1}\right.$, $\left.e_{t+1}^{s}, e_{t+1}^{u}\right)$ in the envelope condition for skilled employment (40) yields an expression whose both sides are multiplied by $c_{t}\left(1-\phi^{s}\right)$ and divided by $n^{s}$ to give:

$$
\begin{aligned}
& \phi^{s}\left(1-\tau_{t}^{s}\right) J_{l^{f, s}}\left(l_{t}^{f, s}, l_{t}^{f, u}\right) Z_{t}^{s}=\left(1-\tau_{t}^{s}\right) w_{t}^{s} Z_{t}^{s}\left(1-\phi^{s}\right)- \\
& \xi\left(1-\phi^{s}\right) c_{t}+\left(1-\gamma_{t}^{s}-p_{t}^{s}\right) \beta E_{t} \phi^{s} \frac{\left(1-\tau_{t+1}^{s}\right) c_{t}}{c_{t+1}} \times \\
& \times J_{l^{f, s}}\left(l_{t+1}^{f, s}, l_{t+1}^{f, u}\right) Z_{t+1}^{s} .
\end{aligned}
$$

Multiplying $E_{t} \frac{c t}{c_{t+1}}$ by $\frac{\widetilde{r}_{t+1}}{\widetilde{r}_{t+1}}$ in $(A 1)$, substituting for $\widetilde{r}_{t+1}^{-1} J_{l^{f, s}}\left(l_{t+1}^{f, s}, l_{t+1}^{f, u}\right)$ using (35) and $J_{l^{f, s}}\left(l_{t}^{f, s}, l_{t}^{f, u}\right)$ using (36), and substituting $\frac{A_{t}^{k}}{c_{t}}$ for $\beta E_{t}\left(\frac{\widetilde{r}_{t+1}}{c_{t+1}}\right)$ in (A1) using the Euler (23) yields:

$$
\begin{aligned}
& \phi^{s}\left[m p l_{t}^{s}-w_{t}^{s}+\left(1-\gamma_{t}^{s}\right) \frac{\varphi^{s}}{q_{t}^{s}}\left(1-\tau_{t}^{v, s}\right)\right]=w_{t}^{s}\left(1-\phi^{s}\right)-\frac{\xi\left(1-\phi^{s}\right) c_{t}}{\left(1-\tau_{t}^{s}\right) Z_{t}^{s}}+ \\
& +\left(1-\gamma_{t}^{s}-p_{t}^{s}\right) E_{t} \phi^{s} \frac{\left(1-\tau_{t+1}^{s}\right)}{\left(1-\tau_{t}^{s}\right)}\left[\frac{\varphi^{s}}{q_{t}^{s}}\left(1-\tau_{t}^{v, s}\right)\right] \frac{Z_{t+1}^{s}}{Z_{t}^{s}} A_{t}^{k} .
\end{aligned}
$$

Simplifying the resulting expression gives the Nash wage rate for skilled workers:

$$
\begin{aligned}
w_{t}^{s}= & \phi^{s}\left\{m p l_{t}^{s}+\left[1-\gamma_{t}^{s}-\left(1-\gamma_{t}^{s}-p_{t}^{s}\right) \times\right.\right. \\
& \left.\left.\times E_{t} A_{t}^{k}\left(\frac{Z_{t+1}^{s}\left(1-\tau_{t+1}^{s}\right)}{Z_{t}^{s}\left(1-\tau_{t}^{s}\right)}\right)\right] \frac{\varphi^{s}}{q_{t}^{s}}\left(1-\tau_{t}^{v, s}\right)\right\}+\frac{\xi\left(1-\phi^{s}\right) c_{t}}{\left(1-\tau_{t}^{s}\right) Z_{t}^{s}} .
\end{aligned}
$$

Working similarly, we can derive the Nash wage rate for unskilled workers:

$$
\begin{aligned}
w_{t}^{u}= & \phi^{u}\left\{m p l_{t}^{u}+\left[1-\gamma_{t}^{u}-\left(1-\gamma_{t}^{u}-p_{t}^{u}\right) \times\right.\right. \\
& \left.\left.\times E_{t} A_{t}^{k}\left(\frac{Z_{t+1}^{u}\left(1-\tau_{t+1}^{u}\right)}{Z_{t}^{u}\left(1-\tau_{t}^{u}\right)}\right)\right] \frac{\varphi^{u}}{q_{t}^{u}}\left(1-\tau_{t}^{v, u}\right)\right\}+\frac{\xi\left(1-\phi^{u}\right) c_{t}}{\left(1-\tau_{t}^{u}\right) Z_{t}^{u}}
\end{aligned}
$$

Alternatively, the wage equations that result from Nash bargaining can be written as in (52)-(53) of the main text. 

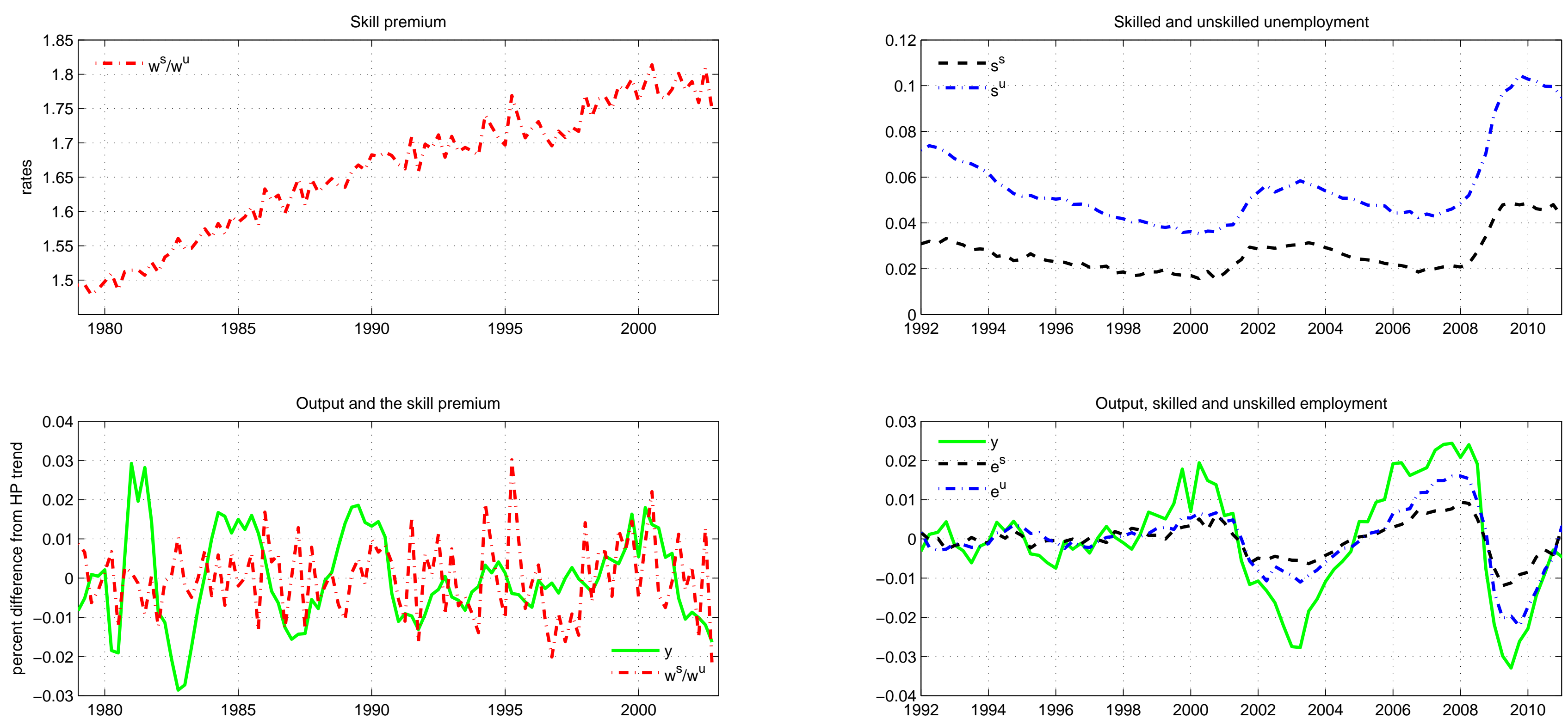

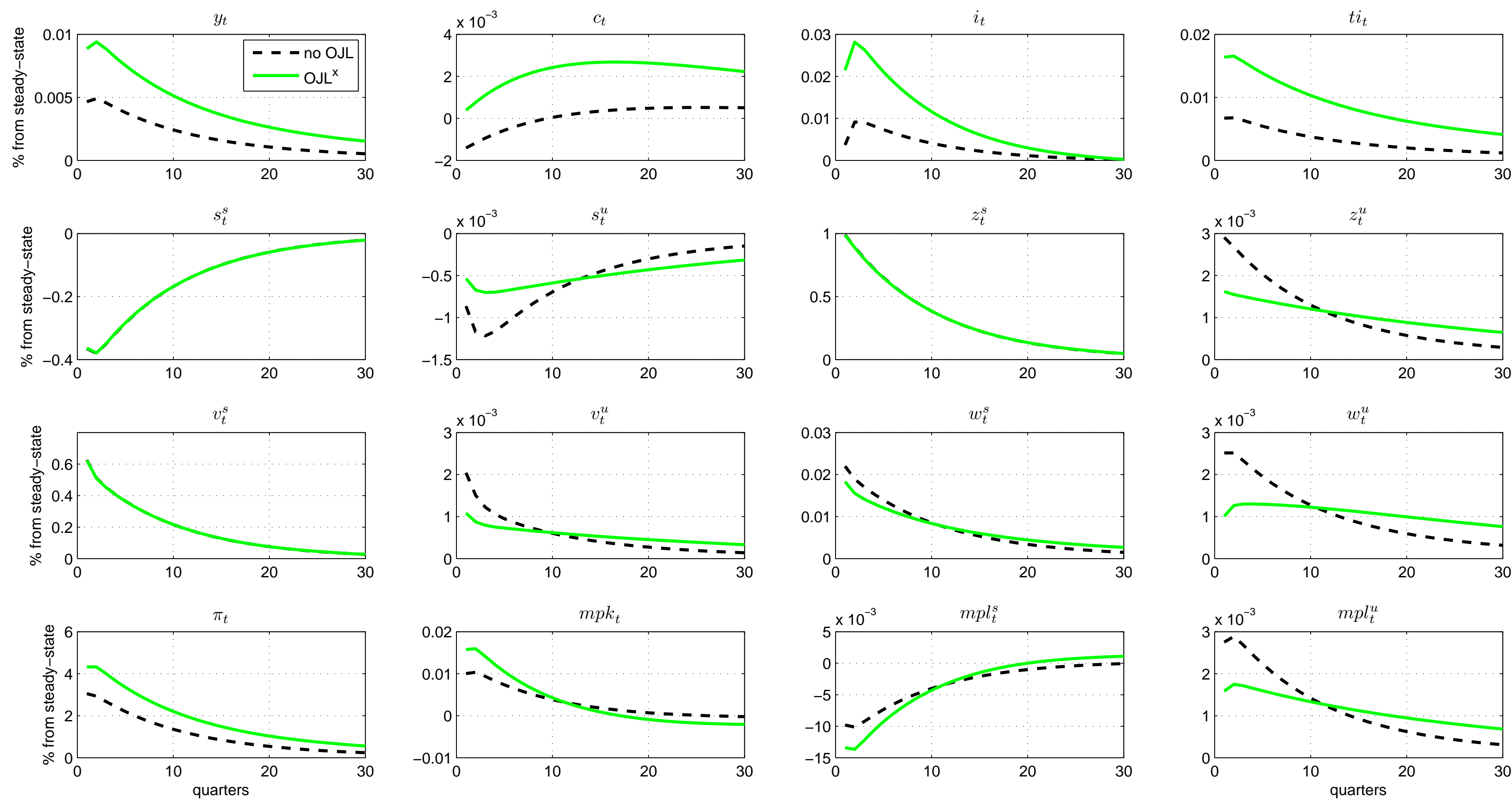

Figure 2: Impulse responses for a temporary $1 \%$ point rise in $\tau_{t}^{\mathrm{v}, \mathrm{s}}$ 

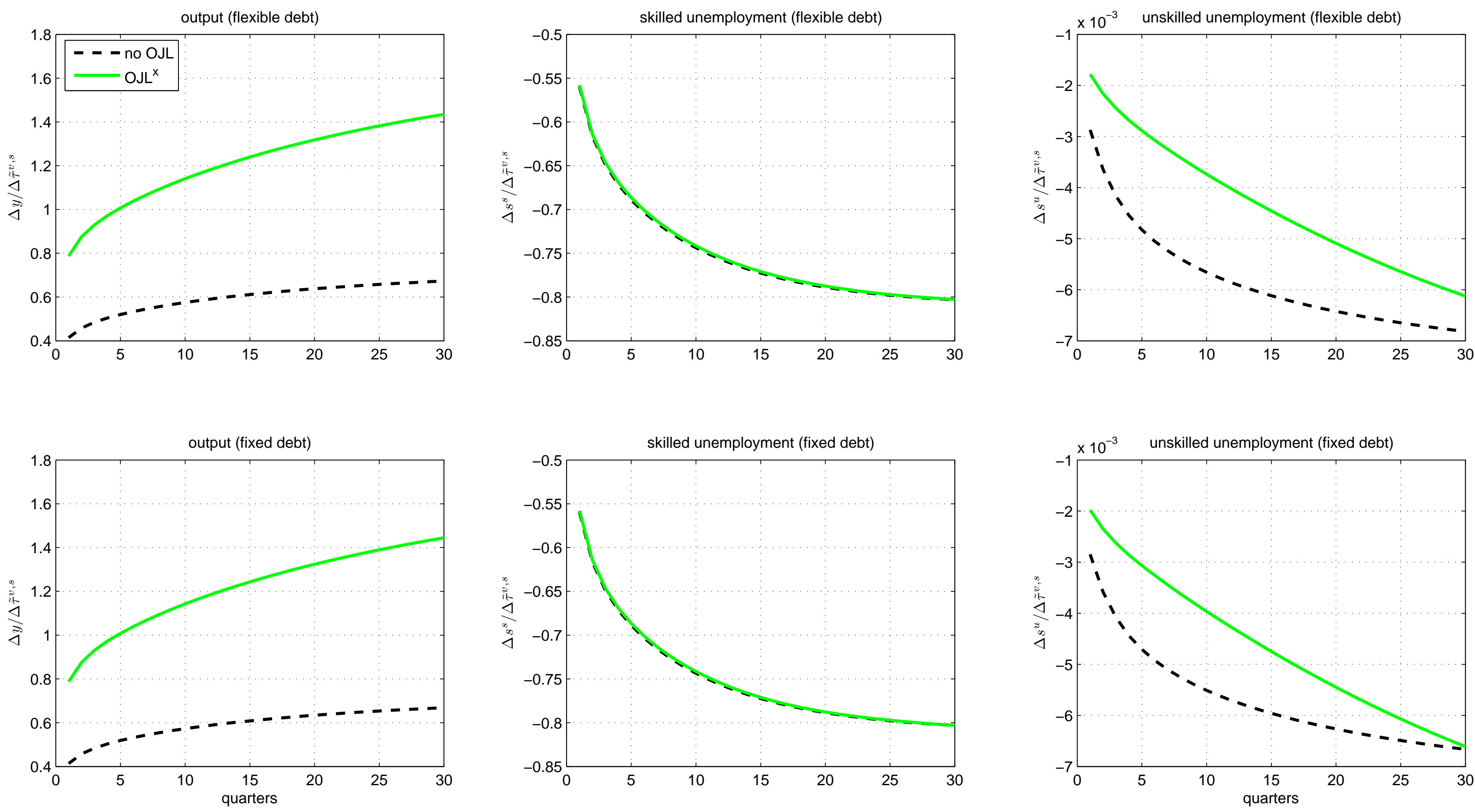

Figure 3: Fiscal multipliers for a temporary $1 \%$ point rise in $\tau_{t}^{v, s}$ 

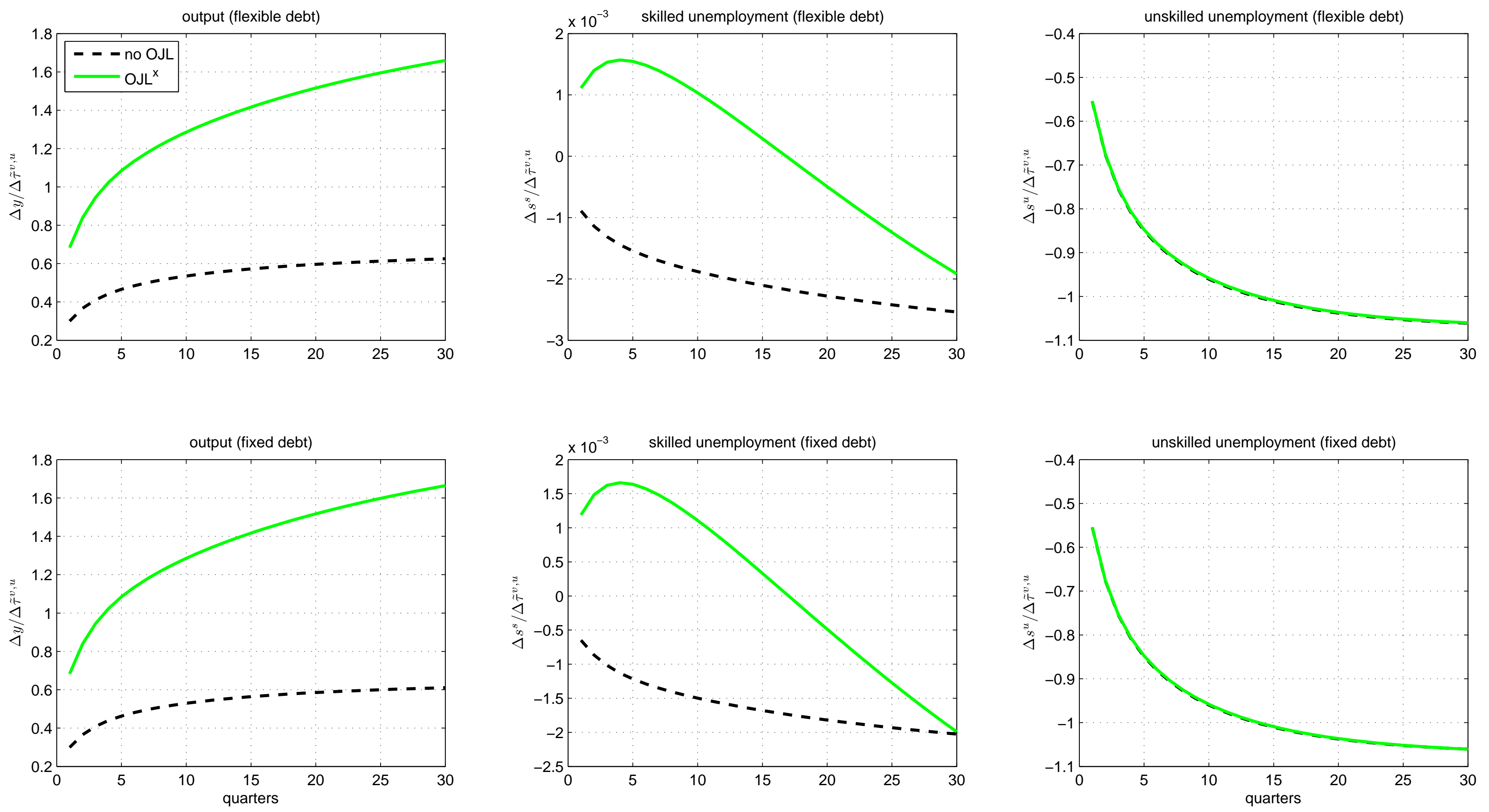

Figure 4: Fiscal multipliers for a temporary $1 \%$ point rise in $\tau_{t}^{\mathrm{v}, \mathrm{u}}$ 

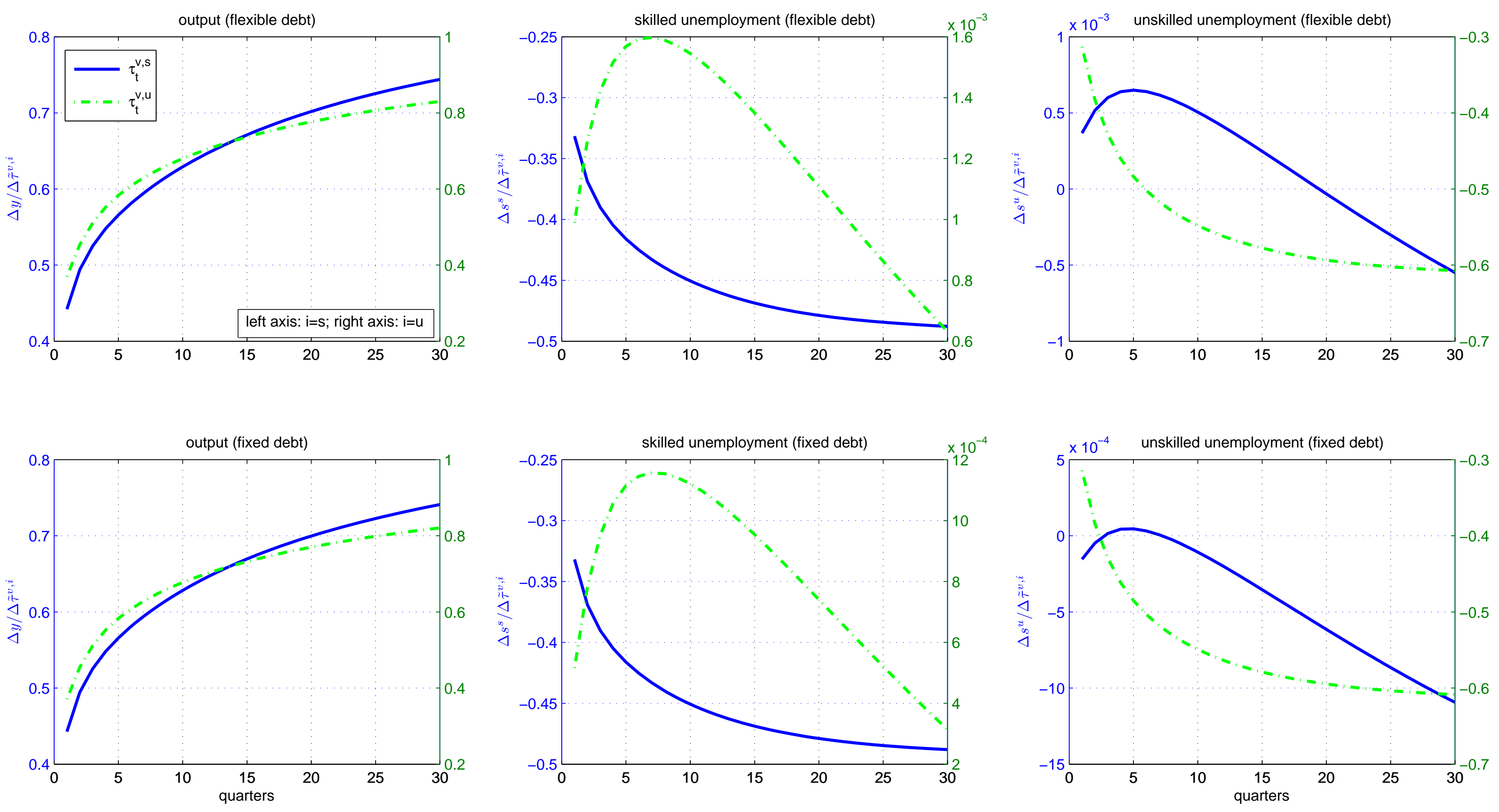

Figure 5: Fiscal multipliers (OJL ${ }^{\mathrm{n}}$ model) for a temporary $1 \%$ point rise in $\tau_{\mathrm{t}}^{\mathrm{v}, \mathrm{i}}$ 

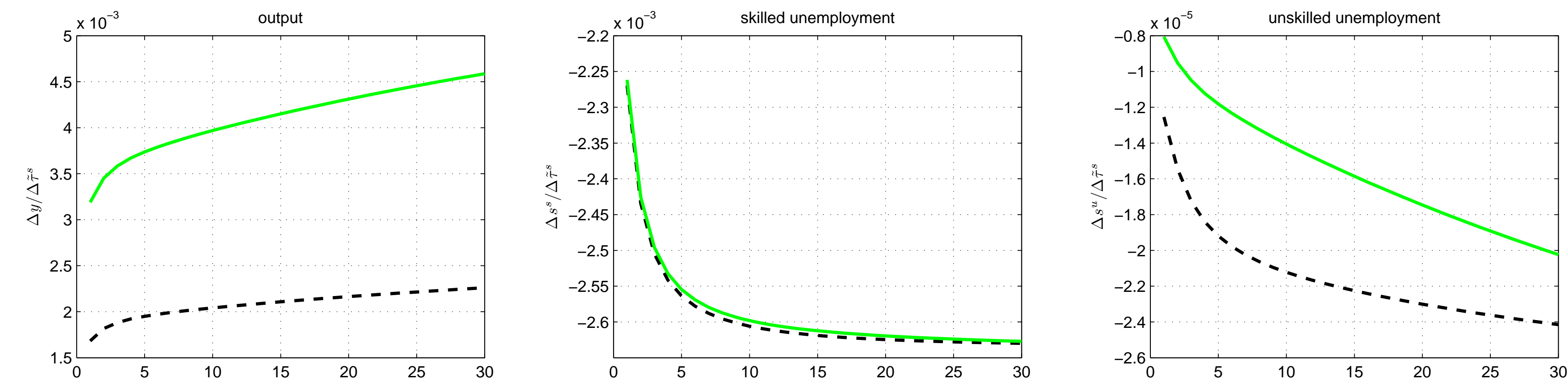

Fiscal multipliers: $\tau_{t}^{u}$
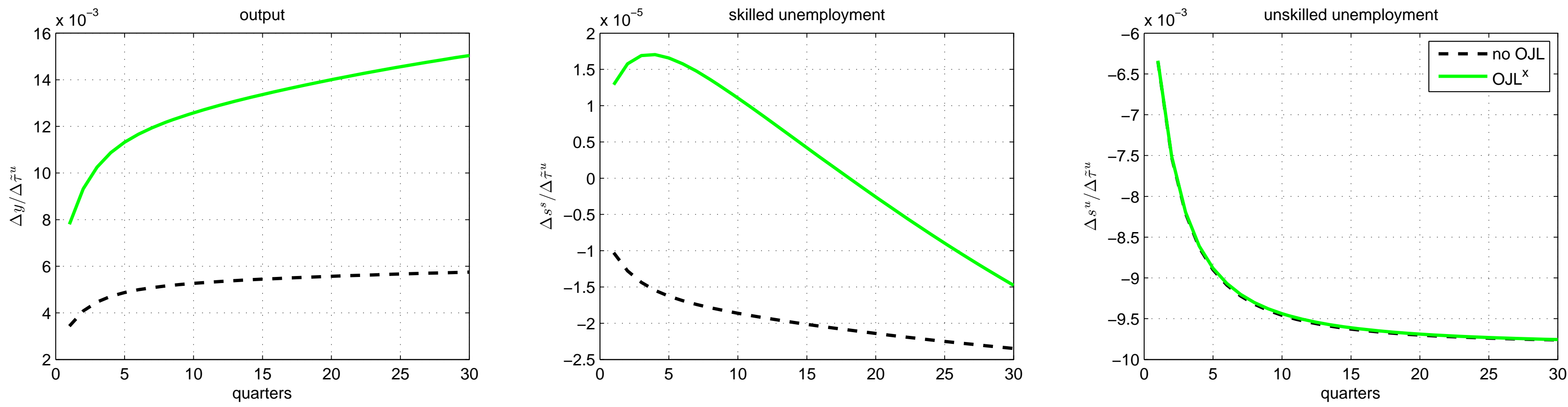

Figure 6: Fiscal multipliers for a temporary $1 \%$ point fall in $\tau_{t}^{\mathrm{s}}$ and $\tau_{t}^{\mathrm{u}}$ (flexible debt) 